\title{
Modeling Sea Ice as a Granular Material, Including the Dilatancy Effect
}

\author{
L.-B. Tremblay and L. A. Mysak \\ Department of Atmospheric and Oceanic Sciences and Centre for Climate and Global Change Research, \\ McGill University, Montreal, Quebec, Canada
}

(Manuscript received 2 July 1996, in final form 1 April 1997)

\begin{abstract}
A dynamic sea ice model based on granular material rheology is presented. The sea ice model is coupled to both a mixed layer ocean model and a one-layer thermodynamic atmospheric model, which allows for an ice albedo feedback. Land is represented by a 6-m thick layer with a constant base temperature. A 10-year integration including both thermodynamic and dynamic effects and incorporating prescribed climatological wind stress and ocean current data was performed in order for the model to reach a stable periodic seasonal cycle. The commonly observed lead complexes, along which sliding and opening of adjacent ice floes occur in the Arctic sea ice cover, are well reproduced in this simulation. In particular, shear lines extending from the western Canadian Archipelago toward the central Arctic, often observed in winter satellite images, are present. The ice edge is well positioned both in winter and summer using this thermodynamically coupled ocean-ice-atmosphere model. The results also yield a sea ice circulation and thickness distribution over the Arctic, which are in good agreement with observations. The model also produces an increase in ice formation associated with the dilatation of the ice medium along sliding lines. In this model, incident energy absorbed by the ocean melts ice laterally and warms the mixed layer, causing a smaller ice retreat in the summer. This cures a problem common to many existing thermodynamic-dynamic sea ice models.
\end{abstract}

\section{Introduction}

The presence of sea ice in polar regions has a substantial influence on the global climate. First, sea ice is highly reflective and substantially reduces the amount of solar radiation absorbed by the surface. Second, it acts as an insulator, reducing the amount of heat, moisture, and momentum flux between the ocean and the atmosphere. Third, the release/absorption of heat during ice formation/melt is an important factor in the atmospheric energy budget. Finally, the transport of ice from one region to another constitutes a flux of freshwater, which strongly influences the circulation in the Arctic Ocean and surrounding seas (e.g., bottom water formation in the North Atlantic).

Since the difficulties in making extensive measurements in ice-covered waters are enormous, our knowledge of the Arctic and Antarctic relies heavily on numerical modeling. To model the ice behavior accurately, it is now recognized that both thermodynamic and dynamic processes are important factors to consider. For example, the ridging of ice in a convergence zone and lead opening in a region of di-

Corresponding author address: Dr. Louis-Bruno Tremblay, Lamont-Doherty Earth Observatory, Columbia University, P.O. Box 1000, Rt. 9W, Palisades, NY 10964-8000.

E-mail: tremblay@1deo.columbia.edu vergence strongly influence the distribution of heat lost from the ocean to the atmosphere, and therefore should be properly included in climate model studies of the Arctic. Further, in the Arctic, where the motion is confined on the periphery by continents, strong interactions between ice floes take place and influence the basinwide ice circulation. Consequently, a good understanding of the interactions between the floes during deformation is of primary importance. As a first step, assumptions about the nature of the material must be made. Past approaches have included modeling the ice as a cavitating fluid (Doronin 1970; Nikiforov et al. 1970; Flato and Hibler 1992), where the ice is assumed to have no shear or tensile strength, or as an elastic plastic or viscous plastic material (Coon et al. 1974; Hibler 1979), based on the observation that the work done in deforming the ice field is rate independent (Coon et al. 1974). In the cavitating fluid approach, the mathematical formulation and implementation is simple. However, the ice velocity tends to be too high due to the absence of frictional forces between the floes. The two plastic approaches yielded a more successful simulation of the ice velocity field and thickness distribution. However, in the elastic-plastic approach (Coon et al. 1974), the history of the state of strain of the ice must be stored since elastic strain is reversible, making the numerical treatment of the resulting set of dynamical equations very complicated (it usually requires a Lagrangian 
approach). This problem is cured in the viscous-plastic approach (Hibler 1979), where small elastic deformation is approximated by creeping flow (Hibler 1977). However, the choice of yield curve and flow rule used in this study can lead to unphysical effects.

In the present paper, we consider the ice to be a slowly deforming granular material (a collection of ice floes) and use a simplified version of the double sliding model developed by Balendran and Nemat-Nasser (1993). This is motivated by observations of the Arctic sea ice cover, which show a distinct lead pattern at various scales that is typical for that type of material (Erlingsson 1988). This model incorporates some features of the previous ice models (Coon et al. 1974; Hibler 1979) but invokes a more general treatment of the deformation rule. In particular, the opening of leads associated with shearing deformation (Stern et al. 1995; Pritchard 1981) follows naturally from the present formulation and eliminates the need for its parameterization as proposed by Stern et al. If we ignore this effect, the present formulation becomes identical to the cavitating fluid model including shear strength, briefly described in Flato and Hibler (1992).

In most previous studies (Hibler and Walsh 1982; Holland et al. 1993), sea ice models and coupled sea ice-ocean models were run with prescribed atmospheric temperature and humidity distribution. This boundary condition on temperature largely determines, a priori, the ice thickness distribution and ice edge position (the air temperature has a strong icecover signature; that is, the air is warm over water and much cooler over ice-covered seas). In the present study, the sea ice model is coupled thermodynamically to a mixed layer ocean and an atmosphere model, which allows for an ice albedo feedback. This is a more stringent test on the validity of the full sea ice model. Also, the energy exchange between the ocean mixed-layer and the ice is done through sensible heat transfer. Consequently, the mixed layer is allowed to warm even when ice is present in the vicinity (Maykut and Perovitch 1987). This will have an influence on the ice retreat in the warm season.

The next section presents supporting evidence for using the present sea ice rheological model, along with the complete description of the model equations for the sea ice, ocean, and land. In section 3, the numerical scheme is described. In section 4 , the model results at the end of a 10-year integration are compared with satellite observations and submarine sonar data. The main conclusions drawn from the simulation results are summarized in section 5 .

\section{Governing equations}

\section{a. Sea ice momentum, continuity, and energy equations}

The governing equations for sea ice, derived from conservation principles, are presented in this section along with appropriate boundary conditions. The momentum balance for the two-dimensional horizontal motion of sea ice can be written as

$$
\begin{gathered}
-\rho_{i} h f \mathbf{k} \times \mathbf{u}_{i}+A\left(\boldsymbol{\tau}_{a}-\boldsymbol{\tau}_{w}\right) \\
+\boldsymbol{\nabla} \cdot \boldsymbol{\sigma}-\rho_{i} h g \nabla H_{d}=0,
\end{gathered}
$$

where $\rho_{i}$ is the sea ice density, $h$ the mean ice thickness, $f$ the Coriolis parameter, $\mathbf{k}$ a unit vector normal to the ice surface, $\mathbf{u}_{i}$ the ice velocity, $A$ the ice concentration (percentage of a grid cell covered by ice), $\boldsymbol{\tau}_{a}$ the wind shear stress on the top ice surface, $\boldsymbol{\tau}_{w}$ the ocean drag on the sea ice flow, $\boldsymbol{\sigma}\left(\sigma_{i j}\right)$ the vertically integrated internal ice stress (normal or shear) acting on a plane perpendicular to the $i$ axis and in the $j$ direction, $g$ the gravitational acceleration, and $H_{d}$ the sea surface dynamic height. Following Gray and Morland (1994), the wind stress and water drag are multiplied by the ice concentration to account for the fact that water may be present in a grid cell. This, however, has a minor effect on the results. A scaling analysis of the momentum equations show that both the advection and acceleration terms can be neglected for sea ice simulation over the whole Arctic using monthly averaged climatological wind stress (Thorndike 1986). The air $\left(\boldsymbol{\tau}_{a}\right)$ and water $(\boldsymbol{\tau})_{w}$ stresses are obtained from a simple quadratic law with constant turning angle (McPhee 1975):

$$
\begin{gathered}
\boldsymbol{\tau}_{a}=\underbrace{\rho_{a} C_{d a}\left|\mathbf{u}_{a}^{g}\right|}_{C_{d a}^{\prime}}\left(\mathbf{u}_{a}^{g} \cos \theta_{a}+\mathbf{k} \times \mathbf{u}_{a}^{g} \sin \theta_{a}\right) \\
\boldsymbol{\tau}_{w}=\underbrace{\rho_{w} C_{d w}\left|\mathbf{u}_{i}-\mathbf{u}_{w}^{g}\right|}_{C_{d w}^{\prime}} \mid\left[\left(\mathbf{u}_{i}-\mathbf{u}_{w}^{g}\right) \cos \theta_{w}\right. \\
\left.\quad+\mathbf{k} \times\left(\mathbf{u}_{i}-\mathbf{u}_{w}^{g}\right) \sin \theta_{w}\right],
\end{gathered}
$$

where $\rho_{a}$ and $\rho_{w}$ are the air and water densities, $C_{d a}$ and $C_{d w}$ the air and water drag coefficient, $\mathbf{u}_{a}^{g}$ and $\mathbf{u}_{w}^{g}$ the geostrophic wind and ocean current, and $\theta_{a}$ and $\theta_{w}$ the wind and water turning angles. In the above equation for the wind shear stress, the ice speed is considered small compared to the wind speed and is therefore neglected.

The ice strength in this model is a function of both the mean ice thickness $h$ and ice concentration $A$ (percentage of a grid cell covered by ice). For this reason, a conservation law for both quantities, derived by averaging the two-dimensional continuity equation, is necessary:

$$
\begin{gathered}
\frac{\partial h}{\partial t}+\nabla \cdot\left(h \mathbf{u}_{i}\right)=S_{h}+K_{h} \nabla^{2} h \\
\frac{\partial A}{\partial t}+\nabla \cdot\left(A \mathbf{u}_{i}\right)=S_{A}+K_{A} \nabla^{2} A,
\end{gathered}
$$

where $K_{h}$ and $K_{A}$ are the diffusion coefficients for ice thickness and concentration, and $S_{h}$ and $S_{A}$ are the thermodynamic source terms given by 


$$
\begin{aligned}
& S_{h}=\frac{1}{\rho_{i} L_{f}} \begin{cases}A\left(Q_{i a}-Q_{o i}\right)+(1-A) Q_{o a}, & T_{o}=T_{o f}, Q_{o a}>0 \\
A\left(Q_{i a}-Q_{o i}\right), & \text { otherwise }\end{cases} \\
& S_{A}=\frac{1}{\rho_{i} L_{f}} \begin{cases}(1-A) Q_{o a} / h_{0}, & T_{o}=T_{o f}, Q_{o a}>0 \\
A \rho_{i} L_{f} S_{h} / 2 h, & S_{h}<0,\end{cases}
\end{aligned}
$$

where $L_{f}$ is the latent heat of fusion; $Q_{i a}$ and $Q_{o a}$ the net ice and oceanic heat fluxes to the atmosphere due to longwave $\left(Q_{\mathrm{lw}-\mathrm{up}}, Q_{\mathrm{lw}-\mathrm{down}}\right)$, sensible $\left(Q_{\text {sens }}\right)$, latent heating $\left(Q_{\text {lat }}\right)$, and shortwave radiation $Q_{\text {sw }}$ (see Fig. 1); $\left(Q_{o i}\right)$ the sensible heat flux from the water to the ice; $h_{0}$ a fixed demarcation thickness between thin and thick ice (Hibler 1979); and $T_{o}$ and $T_{o f}$ the temperature and freezing point temperature of the ocean. In Eq. (5), the ice concentration is restricted to lie between zero and one using a mechanical sink term.

In most existing ice thermodynamic models, incident energy absorbed by the ocean mixes horizontally and melts ice until no ice is present in a grid box. In this manner, the ocean temperature can only rise above the freezing point after all ice is melted. In the present model the ocean is allowed to warm up even though ice is present in a grid cell. The transfer of heat between the ocean and the ice is achieved through sensible heating in a similar manner as between the ice and the atmosphere. Under winter growth conditions, the formation of ice due to $Q_{o a}$ will only occur once the ocean temperature reaches the freezing point. During the melting period, incident energy absorbed by the ocean will partly warm up the mixed layer and partly be used to melt ice. Measurements by Maykut and Perovich (1987) suggest that $80 \%$ of the incident energy on the ocean will warm up the mixed layer. This will give a more realistic ice retreat during the melting season.
For the case of ice-atmosphere heat transfer, the various heat fluxes are defined as

$$
\left.\begin{array}{rl}
Q_{\mathrm{sw}} & =Q_{0}\left(1-\alpha_{a}\right)\left(1-a_{a}\right)\left(1-\alpha_{i}\right) \\
Q_{\text {sens }} & =\rho_{a} C_{\mathrm{sens}}\left|\mathbf{u}_{a}\right| C_{p a}\left(T_{i}-T_{a}\right), \\
Q_{\mathrm{lat}} & =\rho_{a} C_{\mathrm{lat}}\left|\mathbf{u}_{a}\right| L_{s}\left(q_{i}-q_{a}\right) \\
Q_{\mathrm{lw}-\text { down }} & =\epsilon_{a} \sigma T_{a}^{4}, \quad Q_{\mathrm{lw}-\mathrm{up}}=\epsilon_{i} \sigma T_{i}^{4},
\end{array}\right\}
$$

where $Q_{0}$ is the daily averaged flux of solar radiation (Zillman 1972), $\alpha_{a}$ and $\alpha_{i}$ the atmospheric and ice albedo, $a_{a}$ the atmospheric absorptivity to shortwave radiation, $C_{\text {sens }}$ and $C_{\text {lat }}$ the sensible and latent heat transfer coefficients, $\epsilon_{a}$ and $\epsilon_{i}$ the atmospheric and ice emissivities, $\sigma$ the Stefan-Boltzmann constant, $C_{p a}$ the specific heat of air, $L_{s}$ the latent heat of sublimation, $T_{a}$ and $T_{i}$ the air and ice temperature, and $q_{i}$ and $q_{a}$ the ice surface (assumed saturated) and atmospheric specific humidities given by

$$
q_{i}=q_{s}=\frac{0.622 e_{\mathrm{sat}}}{P_{s}-0.378 e_{\mathrm{sat}}}, \quad q_{a}=0.8 q_{s},
$$

where

$$
e_{\text {sat }}=611 \times 10^{A_{1}\left(T_{s}-273.13\right) /\left(T_{s}-A_{2}\right)}
$$

and $P_{s}$ is the sea level pressure (considered constant). In Eq. (9), the relative humidity of the atmosphere is considered constant (80\%), and the dependence of $A_{1}$

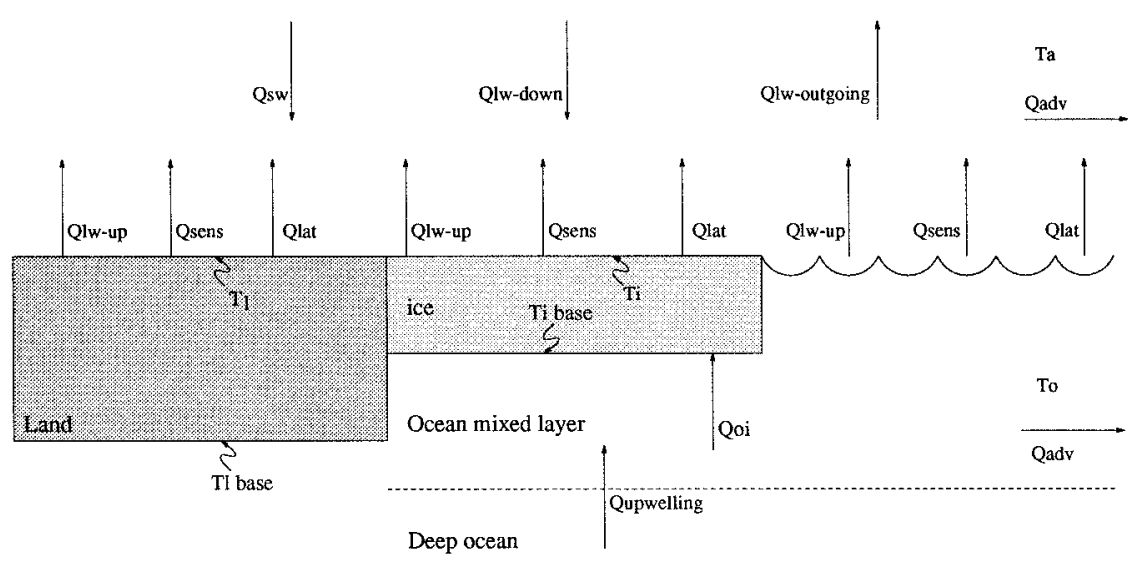

FIG. 1. Heat fluxes over a grid cell. Ocean-atmosphere, ice-atmosphere, land-atmosphere, and ocean-ice heat fluxes are defined positive upward. Note that the shortwave energy absorbed by the surface depends on the surface albedo. The terms $Q_{\text {adv }}$ for the atmosphere and ocean are given in Eqs. (11) and (12). 
and $A_{2}$ on ice concentration is ignored. Similar expressions [Eqs. (8) and (9)] are used for the ocean-atmosphere and ocean-ice heat transfers.

Up to this point, the momentum and continuity equations have been presented. A thermodynamic equation for the ice is also needed to determine the ice surface temperature. The steady-state energy equation for the ice takes the form

$$
K_{i} \frac{\partial^{2} T_{i}}{\partial z^{2}}=0
$$

where $K_{i}$ is the ice thermal conductivity. For ice thicknesses less than $2 \mathrm{~m}$, the time-dependent term involving the thermal capacitance of the ice can be neglected in the energy equation. This approximation is valid for a large part of the Arctic. However, in some regions, the ice can be as thick as $6 \mathrm{~m}$, and this simplification is expected to result in a slight shift in the phase of the seasonal cycle (Holland 1993).

\section{b. Atmosphere, ocean, and land models}

The sea ice model is coupled above to a one-layer thermodynamic model of the atmosphere and below to an ocean mixed layer. Also, the continents are represented by a 6-m-thick layer of conducting material with constant base temperature. The relevant conservation of energy equations are used to compute the temperature of the atmosphere $\left(T_{a}\right)$, ocean $\left(T_{o}\right)$, and land $\left(T_{l}\right)$; these take the form

$$
\begin{aligned}
\rho_{a} C_{p a} H_{a} \nabla \cdot\left(\mathbf{u}_{a}^{g} T_{a}\right)= & \lambda\left[(1-A) Q_{o a}+A Q_{i a}\right] \\
& +(1-\lambda) Q_{l a} \\
& -Q_{\text {lw-out }}+K_{a} \nabla^{2} T_{a}, \\
\rho_{w} C_{p w} H_{o}\left(\frac{\partial T_{o}}{\partial t}+\nabla \cdot\left(\mathbf{u}_{w}^{g} T_{o}\right)\right)= & -(1-A) Q_{o a}-A Q_{o i} \\
& +Q_{\text {upwelling }}+K_{o} \nabla^{2} T_{o}, \\
K_{l} \frac{\partial^{2} T_{l}}{\partial z^{2}}= & 0
\end{aligned}
$$

where $C_{p w}$ is the specific heat capacity for water; $H_{a}$ and $H_{o}$ the atmosphere scale height and the ocean mixedlayer depth; $\lambda$ a land mask parameter (equal to 0 over land and to 1 otherwise); $Q_{l a}$ the energy flux to the atmosphere from the land due to longwave, sensible, latent heating and shortwave radiation; $Q_{\text {lw-out }}$ the longwave radiation lost to space; $Q_{\text {upwelling }}$ the energy flux into the mixed layer from the upwelling of warm water from the deep ocean; $K_{a}$ and $K_{o}$ the atmosphere and ocean diffusion coefficients; $K_{l}$ the land thermal conductivity; and $T_{l}$ the land temperature. In the above equations, the advective terms are represented as $Q_{\text {adv }}$ in Fig. 1. The response time of the atmosphere is short due to its low heat capacity; consequently, the time- dependent term in the energy equation for the atmosphere will be neglected. Physically this implies that the atmosphere is always in equilibrium with the ocean or land. To calculate $Q_{\text {upwelling }}$, it is assumed that when ice forms it rejects all of its salt; for a salinity and temperature difference of $5 \mathrm{ppt}$ and $2^{\circ} \mathrm{C}$ between the deeper ocean and surface waters, this results in heat flux into the mixed layer approximately equal to $10 \%$ of the latent heat flux released during ice formation.

\section{c. Sea ice rheology}

In order to close the system of equations, the stresses ( $\boldsymbol{\sigma})$ must be written in terms of the basic variables describing the ice behavior. In mathematical form this is written as follows:

$$
\sigma_{k l}=f_{k l}\left(u_{i, j}, h, A, T_{i}\right),
$$

where $u_{i, j}=\partial u_{i} / \partial x_{j}$ is the velocity gradient consisting of a symmetric part $\dot{\epsilon}_{i j}=\left(u_{i, j}+u_{j, i}\right) / 2$, the stretching (strain rate) tensor, and an antisymmetric part $\dot{\Omega}_{i, j}=\left(u_{i, j}\right.$ $\left.-u_{j, i}\right) / 2$, the spin (angular velocity) tensor, and $T_{i}$ is the ice temperature. In the model proposed here, the dependence of the stresses on $\dot{\Omega}_{i, j}$ and ice temperature will be ignored. These equations are called the constitutive relations and are material dependent. Thus, assumptions about the type of material and its behavior in deformation must first be postulated.

The sea ice cover consists of many floes and is assumed to be a large-scale granular material in slow continuous deformation. A granular material is a collection of a large number of discrete solid grains (e.g., ice floes) with accompanying interparticle voids. These voids are usually filled with fluid such as air or water and, strictly speaking, the flow of a granular mass is a multiphase flow. However, for closely packed material or when the density of the interstitial fluid is small compared to the particle density, the transfer of momentum is done mainly by the particles and the flow can be considered as a dispersed single-phase flow rather than a two-phase flow. The flow of sea ice is considered to fall in the former category.

Depending on the local stress conditions, sea ice can behave as an elastic solid, a plastic solid, or a fluid. During its elastic-solid behavior, sea ice can resist large forces induced by winds and ocean currents in the presence of boundaries, with relatively small deformation (compared to plastic deformation). However, much of this resistence occurs at frictional bonds between the floes, and as such the ice strength is limited by the loads those bonds can take. When the force transmitted across intergranular contact points exceeds certain critical values for compressive, shear, and tensile loads (failure criterion), the structure collapses and it starts to flow. When the compressive load limit is reached, the floes override one another forming a ridge (Hopkins 1994); when the tensile load limit is reached (equal to zero, no cohesion) the floes drift freely without interacting with 
a)

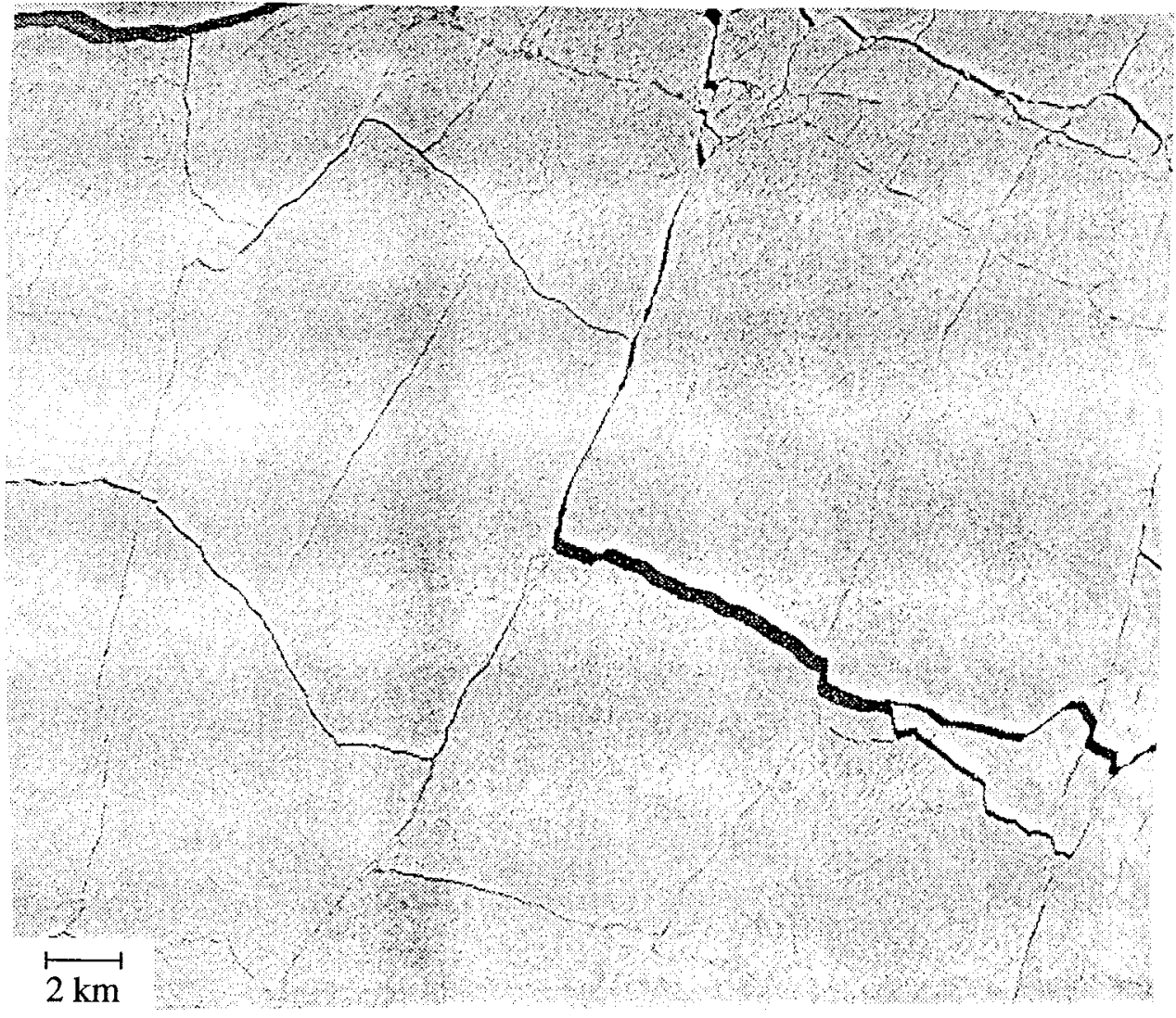

FIG. 2. (a) Photograph of the Arctic pack ice taken at an altitude of $6.1 \mathrm{~km}$ (reproduced from Coon et al. 1974). (b) Satellite picture of the pack ice north of Greenland and Ellesmere Island (reproduced from Kozo et al. 1992). (c) SMM/I brightness temperature of the Arctic (NSIDC data). The full scale is about $20 \mathrm{~km}$ for (a), $1000 \mathrm{~km}$ for (b), and $2500 \mathrm{~km}$ for (c).

one another; and when the shear load limit is reached, the failure consists of a group of several floes sliding or rolling relative to one another along sliding lines roughly aligned with the stress characteristics in the material. Examples of such sliding lines are shown in Fig. 2 for different length scales. Earlier work by Marko and Thompson (1977) explained the presence of those features by brittle material fracture. Later, Pritchard (1988) demonstrated that plastic models used for sea ice modeling can explain the presence of such lead patterns. For sea ice, the relative ice speed across sliding lines is small, and the different floes remain in contact during deformation, allowing friction to act. This is termed the quasi-static flow regime [see Babic et al. (1990) for a detailed classification]. In the rapid flow regime, the interactions between the floes are modeled as inelastic collision. This type of approach has been used in the ice margin region where the floe speeds are typically larger (Shen et al. 1986). For a review on high speed granular flow, see Campbell (1990) and Hutter and Rajagopal (1994).

From the above considerations, we derive macroscopic constitutive relations, based on the microscopic behavior of the floes, that model the large-scale motion of sea ice. The model presented here is based on the double sliding model of Balendran and Nemat-Nasser (1993), in which inelastic deformation is assumed to consist of two superimposed shear deformations along sliding lines obtained from the Mohr-Coulomb failure criterion, or ridging when the average normal stress at a point exceeds the ice strength in compression. However, the elastic deformation, the dependence of the stresses on the rotation tensor, and the variable internal angle of friction are neglected (the deformation history of the material is ignored). These simplifications make this model suitable for climate studies, which involve longer timescales.

Consider the stresses acting on an ice element, as shown in Fig. 3a (compressive stresses are defined as negative). Since the stress tensor is symmetric, it will always be possible to diagonalize it with a pure rotation of the coordinate axes (see Fig. 3b). The stresses acting on the rotated element are the maximum and minimum normal stresses acting at a point and are called the principal stresses $\left(\sigma_{1}\right.$ and $\left.\sigma_{2}\right)$; the shear stresses acting on the rotated element vanish identically. The principal stresses can also be interpreted as the eigenvalues of the stress tensor matrix, and the angle of rotation $\psi$ between 
b)

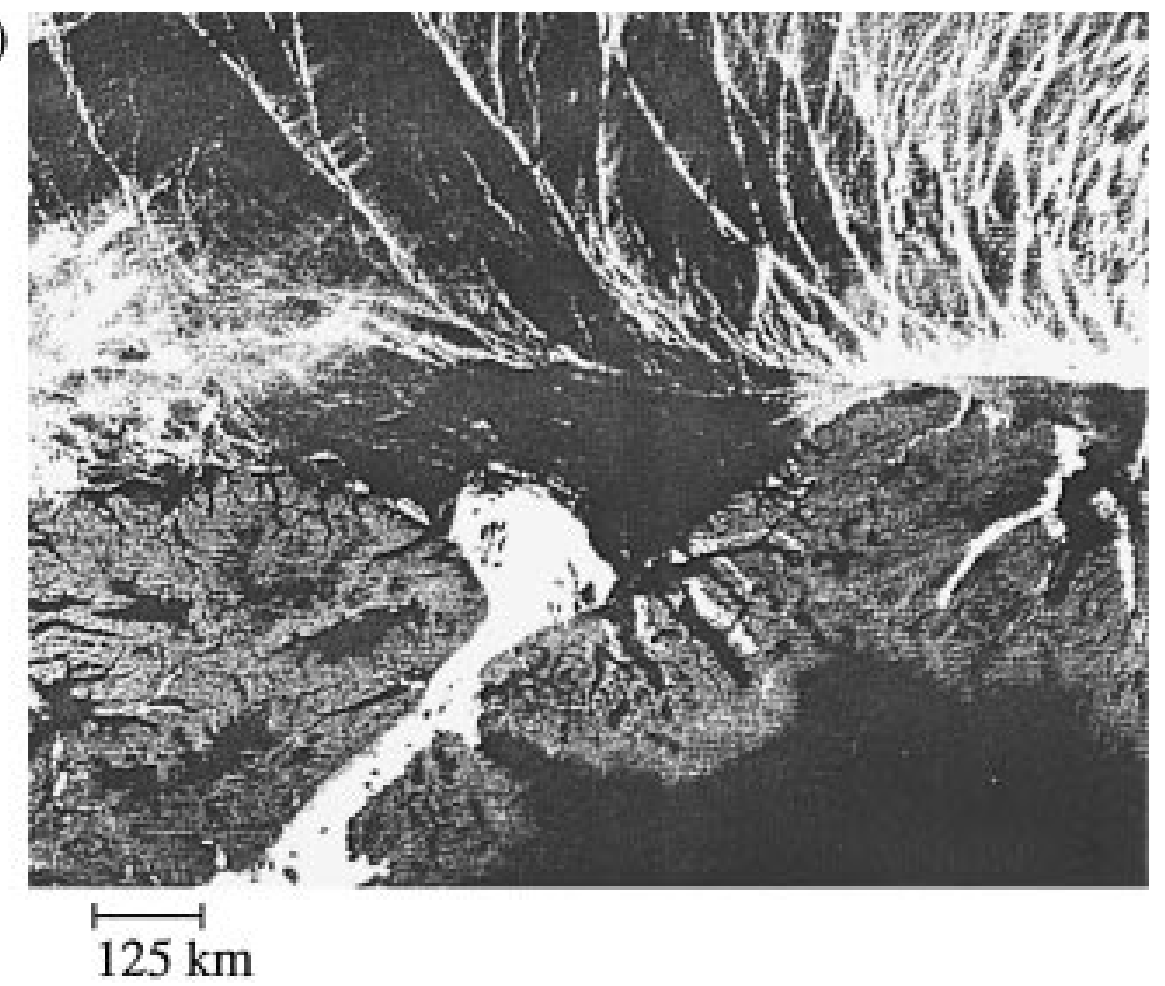

c)

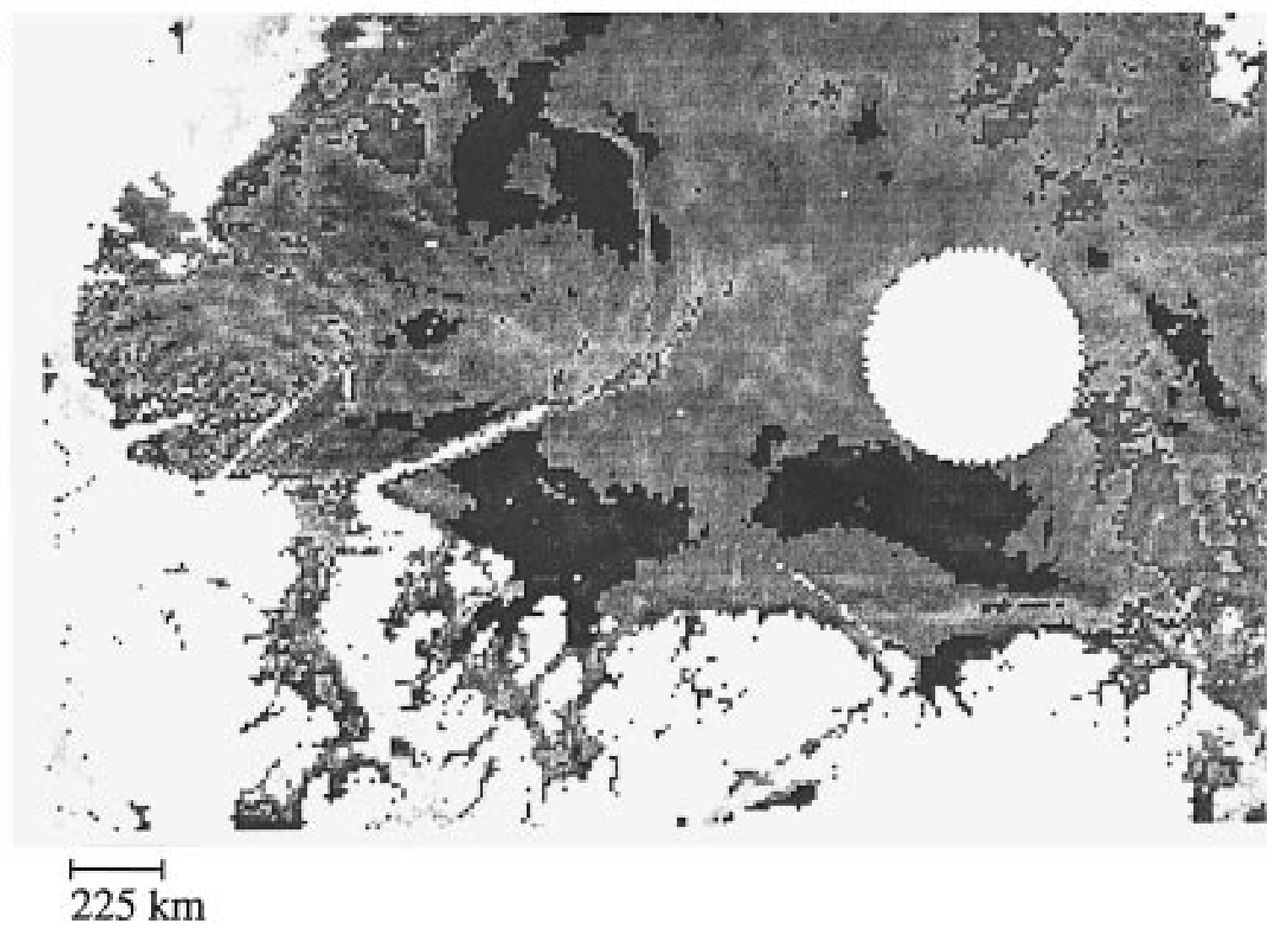

FIG. 2. (Continued) 


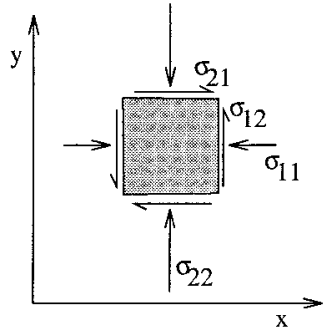

a)

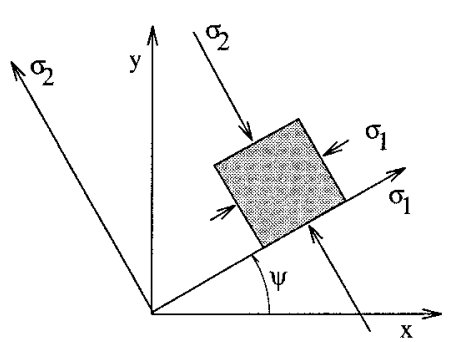

b)
FIG. 3. State of stress at a point in model coordinates (a) and principal stress coordinates (b).

the two coordinate systems can be deduced from the rotation matrix composed of the two normalized eigenvectors. These new coordinate axes will provide a useful reference to determine the failure criterion of a given material. Mathematically, they can be written in terms of the two stress invariants, the average normal stress (or pressure) $p$, and the maximum shear stress $q$, as follows:

$$
\sigma_{1}=-p+q, \quad \sigma_{2}=-p-q,
$$

where

$$
p=-\frac{\sigma_{i i}}{2}, \quad q=\left(\frac{\sigma_{i j}^{\prime} \sigma_{i j}}{2}\right)^{1 / 2}, \quad \sigma_{i j}^{\prime}=\sigma_{i j}+p \delta_{i j},
$$

and the angle $\psi$ between the $\mathrm{x}-\mathrm{y}$ and the principal stress axes satisfies the following relation:

$$
\tan 2 \psi=\frac{2 \sigma_{12}}{\sigma_{11}-\sigma_{22}}
$$

Similar expressions can also be derived for the strain rate tensor $\dot{\boldsymbol{\epsilon}}$. The strain rate invariants, $\dot{\boldsymbol{\epsilon}}_{1}$ and $\dot{\boldsymbol{\epsilon}}_{2}$, can be physically interpreted as the divergence and the maximum shear strain rate at a point [see Ukita and Moritz (1995) for a review].

\section{1) FAILURE CRITERION}

In the following, we consider the planar deformation of sea ice (two-dimensional horizontal flow of cylindrical ice floes), with occasional overriding of adjacent ice floes. First, a failure criterion is required to specify the transition between elastic-solid and plastic-solid/fluid behavior. This will lead us into section $2 \mathrm{c}(3)$, where constitutive relations that model the resulting deformation are given.

For sea ice deformation along a sliding line, the failure criterion, based on Coulomb's friction law, can be written as follows:

$$
\tau_{s}=-\sigma_{s} \tan \phi
$$

where $\phi$ is the effective angle of friction and $\tau_{s}$ and $\sigma_{s}$ are the shear and normal stresses acting on the sliding plane (see Fig. 4). The above expression is exactly equivalent to dynamic friction between two dry surfaces

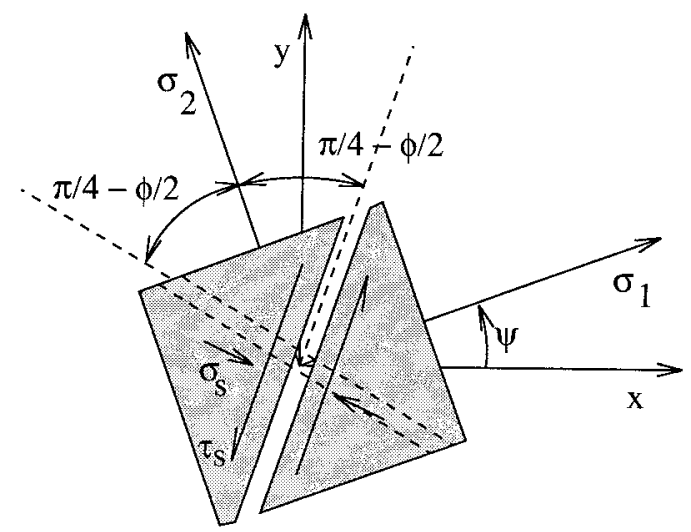

FIG. 4. The orientation of the sliding lines (dashed) with respect to the $x-y$ and $\sigma_{1}-\sigma_{2}$ coordinate systems. The second sliding line is shown as a double dashed line for the sake of clarity.

where the frictional force is proportional to the normal force; the constant of proportionality is the coefficient of friction $(\tan \phi)$. For stress ratios $\tau /(-\sigma)$ less than $\tan \phi$, sea ice behaves as an elastic solid and, when the stress ratio is equal to $\tan \phi$, it flows like a fluid. There are two planes on which this stress ratio reaches its maximum value and they are situated symmetrically about the principal stress axis $\sigma_{2}$ at angles of $\pm(\pi / 4-$ $\phi / 2$ ) (Fig. 4). Writing the stresses $\sigma_{s}$ and $\tau_{s}$ in terms of the stress invariants, the sliding criterion [Eq. (15)] can be rewritten as

$$
q=p \sin \phi
$$

with

$$
\tau_{s}=q \cos \phi \quad \sigma_{s}=-(p-q \sin \phi) .
$$

In the above equation, the pressure $p$ is limited to a maximum value $P_{\max }$, which is a function of the local ice thickness and concentration. This can be parameterized as follows (Hibler 1979):

$$
P_{\max }=P^{*} h \exp [-C(1-A)],
$$

where $P^{*}$ is the ice strength per meter ice thickness and $C$ is the ice concentration parameter. Note that for typical values of $C, P_{\max }$ can be considered equal to zero for $A$ equal to zero. When $p$ reaches this maximum value, the ice can no longer support the compressive load and the floes override each other-that is, a ridge forms. The failure (yield) criterion described above [Eq. (16)] is shown in Fig. 5a in stress-invariant space and in Fig. $5 b$ in principal stress space. This yield curve is equivalent to the straight portion of the ice-cream-cone yield curve, favored by Coon (1974) (Fig. 5b). The elliptical yield curve used by Hibler (1979) was chosen in an attempt to represent the ice-cream-cone yield curve of Coon while maintaining mathematical simplicity. Note, however, that the ellipse lies in part in the positive principal stress quadrants and therefore has some tensile strength (cohesion).

The failure criterion marks the boundary between 

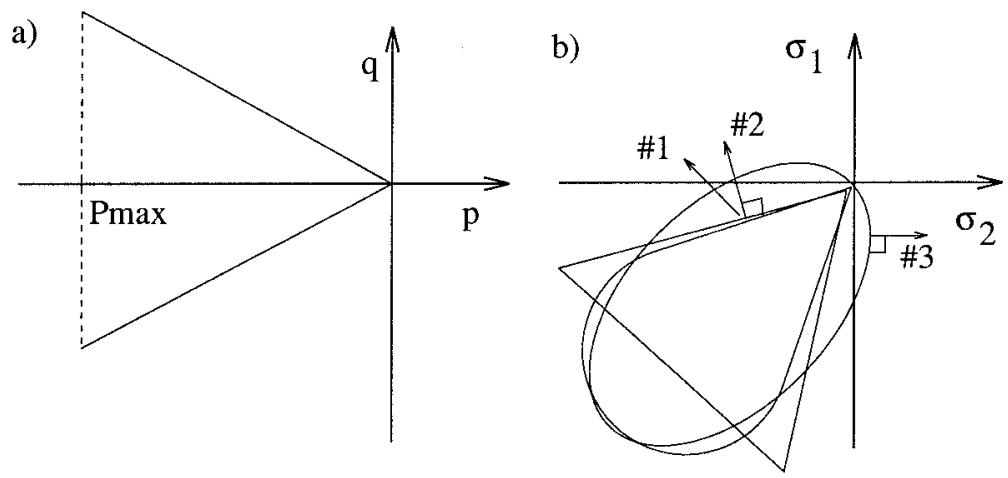

FIG. 5. Mohr-Coulomb failure criteria in stress invariant space (a), in principal stress space (b), and the ice-cream-cone and elliptical yield curve in principal stress space (b). Note that the principal stress axes are orientated at $45^{\circ}$ from the stress invariant axes. Also, when there is no rotation, the principal axes of strain coincide with the principal axes of stress.

elastic and inelastic (plastic) behavior of sea ice. When the stresses lie within the yield curve, sea ice behaves as an elastic solid and negligibly small deformation occurs; when the stresses lie on the yield curve, there are three possible motions: 1) sliding can take place along a sliding line (solid line in Fig. 5a), 2) ridging can occur when the maximum pressure is reached (dashed line in figure 5a) or 3) free drift can occur when all stresses are zero. From equation 16, the stress tensor in the $x-y$ coordinate system can be written in terms of $p$ and $\psi$ as follows:

$$
\boldsymbol{\sigma}=\left[\begin{array}{cc}
-(p-p \sin \phi \cos 2 \psi) & p \sin \phi \sin 2 \psi \\
p \sin \phi \sin 2 \psi & -(p+p \sin \phi \cos 2 \psi
\end{array}\right]
$$

It remains to relate the angle $\psi$ to the strain rate tensor $\dot{\boldsymbol{\epsilon}}$ and to propose a closure scheme to solve for the pressure $p$. It should be appreciated that shear deformation along sliding lines leads to a rearrangement of the ice floes, and consequently, to a redistribution of the contact normal between individual floes. This causes a change in the material's resistance to shear deformation (a change in $\phi$ ) and may lead to densification or dilatation (larger or smaller ice concentration) of the material, depending on the orientation of the contact normals. The next subsection discusses the link between the effective angle of friction $(\phi)$, the dilatation, and the resulting deformation in the ice field.

\section{2) Dilatation}

Deformation of a granular mass comes from the relative displacement of individual granules along planes tangent to the ice floes at an active contact normal (see dashed lines in Fig. 6). The angle between those planes (microscopic plane of motion) and the macroscopic sliding plane is called the angle of dilatancy and is denoted by $\delta$. Normal forces at contacting points with positive angle of dilatancy (Fig. 6a) tend to oppose relative motion and contribute to the overall resistance of the material to shear deformation, and those with negative angle of dilatancy (Fig. 6b) tend to assist motion and reduce the resistance of the material to shear motion. Also, from the orientation of the microscopic plane of motion and the macroscopic sliding plane, we note that a positive angle of dilatancy leads to a dilatation of the material (shear + divergence) whereas a negative angle of dilatancy leads to a densification of the material (shear + convergence). Therefore, the macroscopic angle of friction of a granular material (or its resistance to shear motion) depends not only on the type of material but also on the distribution of the contact normal, and is closely related to dilatation/densification; however, the microscopic angle of friction $(\mu)$ between two distinct floes is considered a constant property of the material.

A relationship between the effective angle of friction $(\phi)$, the ensemble average angle of dilatancy over a grid cell $(\delta)$, and the microscopic angle of friction $(\mu)$ is presented. For $\delta>0$, the forces on the microscopic plane $(R, F)$ can be written in terms of the forces in the macroscopic plane $(N, T)$ as follows:

$F=T \cos \delta-N \sin \delta, \quad R=T \sin \delta+N \cos \delta$,

where $T=A_{\mathrm{s}} \tau_{\mathrm{s}}, N=A_{\mathrm{s}} \sigma_{\mathrm{s}}$ and $A_{\mathrm{s}}$ is the area of the sliding plane. Similar relations can be written for a negative angle of dilatation. When sliding occurs, the frictional force $F$ is related to the normal force $R$ by (as in Eq. 15)

$$
F=R \tan \mu .
$$

From Eqs. (17), (19), and (20), the macroscopic angle of friction $(\phi)$ can be related to the angle of dilatancy $\delta$ and the microscopic angle of friction $(\mu)$ by

$$
\phi=\delta+\mu \text {. }
$$

In the initial stage of deformation, more and more con- 

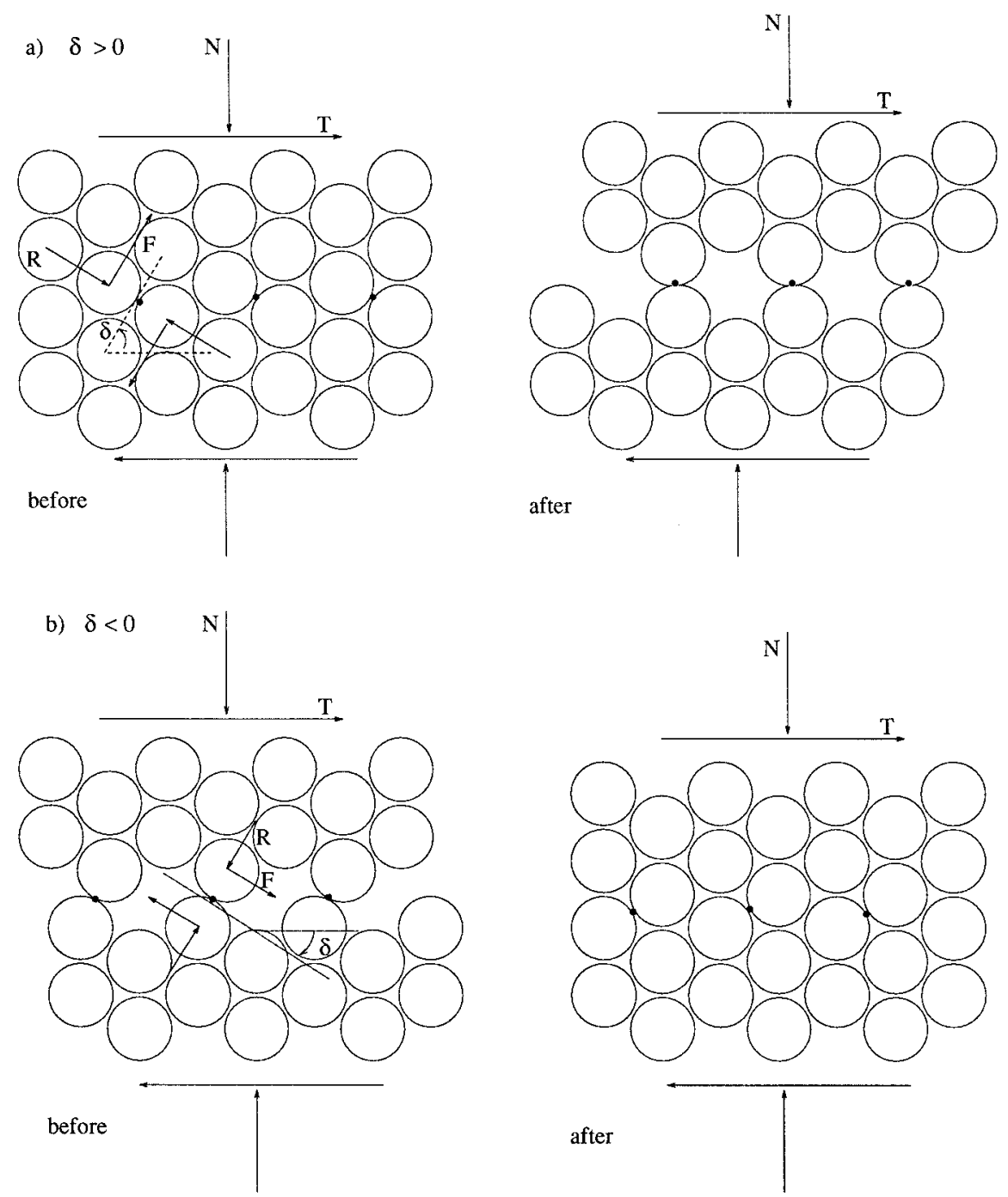

FIG. 6. Forces acting on ice floes for positive (a) and negative (b) angle of dilatancy. The contact points between various floes are shown as dots.

tact normals with positive angles of dilatancy are formed, while contact normals with negative angle of dilatancy are continually lost. This leads to an initial dilatation of the material (opening of leads) and an associated increase of resistance to shear motion $(\phi)$. With time, positive contact normals are eroded and the overall angle of dilatancy and macroscopic angle of friction remain constant. The possibility to detect leads from $\mathrm{SSM} / \mathrm{I}$ brightness temperature data with a $10 \mathrm{~km}$ resolution (Fig. 2) shows that adjacent ice floes not only slide on one another along leads but also move apart, uncovering warm ocean water underneath. Sea ice divergence calculated from synthetic aperture radar (SAR) images (Stern et al. 1995) clearly indicate that opening and closing of leads is present during shear deformation. In this model, this effect comes naturally from considering the microscopic behavior of sea ice in shear deformation and does not rely on parameterization. Other sea ice models using different rheologies have also included the effect of dilatation associated with shear deformation; see, for example, Pritchard (1981) and Flato and Hibler (1991).

To close the problem, an evolution equation for the effective angle of friction $\phi$ is required. Examples of evolution equations for various types of material are given in Balendran and Nemat-Nasser (1993). For this application, the effective angle of friction is assumed to have reached its saturation value and therefore it will be considered constant. This constant is set at $30 \mathrm{deg}$, based on observation made by Overland and Pease (1988).

\section{3) Constitutive Relations}

In this subsection, the constitutive equations relating the stresses $(\boldsymbol{\sigma})$ to the strain rates $(\dot{\boldsymbol{\epsilon}})$ are presented. The 
strain rate can be separated into a plastic and an elastic part $\left(\dot{\boldsymbol{\epsilon}}=\dot{\boldsymbol{\epsilon}}^{p}+\dot{\boldsymbol{\epsilon}}^{e}\right)$. In the model proposed here, only the plastic deformations are kept since the elastic deformations are typically much smaller.

It is assumed that the plastic deformation is due to shearing along the sliding lines and that the rate of shearing is denoted by $\dot{\gamma}$. Note that the rate of shearing is the same on both sliding lines; this follows from the no rotation assumption $\dot{\boldsymbol{\Omega}}=\mathbf{o}$ (see beginning of section $2 \mathrm{c}$ above). Axial strain rate is also present on the sliding lines due to the dilatation/densification of the material. The resulting strain rate tensor, in a coordinate system aligned along a sliding line $(\alpha=1,2)$, takes the following form:

$$
\dot{\boldsymbol{\epsilon}}^{\alpha}=\left[\begin{array}{cc}
0 & \dot{\gamma} \\
\dot{\gamma} & \dot{\gamma} \tan \delta
\end{array}\right] \quad \alpha=1,2 .
$$

The strain rate tensor $(\dot{\boldsymbol{\epsilon}})$ in the $\mathrm{x}-\mathrm{y}$ coordinate system is the sum of the $\dot{\boldsymbol{\epsilon}}^{\alpha}, \alpha=1,2$, rotated by an angle of $\psi \pm(\pi / 4-\phi / 2)$, respectively. The following relationships can be derived from $\dot{\boldsymbol{\epsilon}}$, expressed in the $\mathrm{x}-\mathrm{y}$ coordinate system:

$$
\begin{aligned}
\dot{\epsilon}_{k k} & =2 \dot{\gamma} \tan \delta \\
\dot{\epsilon}_{11}-\dot{\epsilon}_{22} & =2 \dot{\gamma} \frac{\cos (\phi-\delta)}{\cos \delta} \cos 2 \psi \\
2 \dot{\epsilon}_{12} & =2 \dot{\gamma} \frac{\cos (\phi-\delta)}{\cos \delta} \sin 2 \psi
\end{aligned}
$$

From Eqs. (23) and (24), the angle $\psi$ can be written in terms of the deformation field in the following manner:

$$
\tan 2 \psi=\frac{2 \dot{\boldsymbol{\epsilon}}_{12}}{\dot{\epsilon}_{11}-\dot{\boldsymbol{\epsilon}}_{22}} .
$$

This ratio of strain rates also measures the angle between the principal axes of strain rate and the $x-y$ coordinate axes (see section 2c). This indicates that the principal stress axes coincide with the principal strain rate axes; that is, the extreme values of axial strain rates $\left(\dot{\epsilon}_{1}, \dot{\epsilon}_{2}\right)$ will occur where the extreme normal stresses $\left(\sigma_{1}, \sigma_{2}\right)$ are acting. This is not precisely the case in practice, but follows from the no-rotation argument $\dot{\boldsymbol{\Omega}}=\mathbf{o}$.

In the present approach, the deformation varies from pure shear deformation $(\delta=0)$ to shear deformation with divergence $(\delta>0)$ or convergence $(\delta<0)$, depending on the chosen value of $\delta$ [see Eqs. (21) and (22)]. For $\delta=0$, the deformation is represented graphically in Fig. 5b (\#1); in this case, the orientation of the arrow $\left(45^{\circ}\right)$ is such that the principal strains are equal in magnitude but opposite in sign (nondivergent flow, $\dot{\epsilon}_{1}+\dot{\epsilon}_{2}=0$ ). In comparison, when the normal flow rule (Fig. 5b, \#2) is used in conjunction with the ice-creamcone or Mohr-Coulomb yield curve (as in Coon et al. 1974), excessive dilatation results (Spencer 1964), with $\dot{\boldsymbol{\epsilon}}_{1}$ positive and larger in magnitude than $\dot{\boldsymbol{\epsilon}}_{2}\left(\dot{\boldsymbol{\epsilon}}_{1}+\dot{\boldsymbol{\epsilon}}_{2}>\right.$ 0 , divergent flow). When used with the elliptical yield curve (as in Hibler 1979), strong divergent flow results whenever the stress state lies in the first half of the ellipse, where the normal to the yield curve projects onto one or both positive principal strain axes (Fig. 5b \#3). This situation is not realistic and is avoided in the present model. It is also interesting to note that the divergence associated with shearing motion is in effect a new thermodynamic source term in both continuity equations and provides a means to form thicker ice without the need to ridge thick multiyear ice.

Finally, Eq. (22) can be used to close the system of equations and solve for $p$ :

$$
\dot{\boldsymbol{\epsilon}}_{k k}=2 \dot{\gamma} \tan \delta, \quad \text { when } 0<p<P_{\max } .
$$

In the above equation, $\dot{\gamma}$ is taken as the maximum shear strain acting at a point [equal to half the denominator in Eq. (27)]. For $\delta=0$, the above equation reduces to the closure scheme proposed by Flato and Hibler (1992). Substituting (25) into (18), the final constitutive equations are obtained:

$$
\sigma_{i j}=-p \delta_{i j}-\eta \dot{\epsilon}_{k k} \delta_{i j}+2 \eta \dot{\epsilon}_{i, j}
$$

where

$$
\eta=\min \left(\frac{p \sin \phi}{\sqrt{\left(\dot{\epsilon}_{11}-\dot{\epsilon}_{22}\right)^{2}+4 \dot{\epsilon}_{12}^{2}}}, \eta_{\max }\right) .
$$

For small deformation $\left(\dot{\epsilon}_{1}, \dot{\epsilon}_{2}\right)$, the coefficient of friction is constant $\left(\eta=\eta_{\max }\right)$ and sea ice behaves as a very viscous fluid.

\section{Numerical scheme}

The numerical scheme used to solve the governing equations for the thermodynamics of the atmosphere, ice, ocean, and land is presented in this section. Since the time-dependent terms in the ice momentum equation and the atmospheric energy equation are neglected, the ice field and the atmosphere are always in balance with the external forcing. In addition, the coupling between the atmosphere, ice, and ocean model components is only through the thermodynamic equations as the wind and ocean currents are prescribed quantities. These restrictions greatly simplify the solution procedure. The ice thickness, concentration, and ocean temperature fields are first calculated by time stepping the continuity equations (4) and (5) and the ocean energy equation (12). Given the $h$ and $A$ fields, the ice velocity field satisfying the momentum equations (1) can be calculated. The ice surface, land surface, and atmospheric temperature are obtained in a similar manner from the new $T_{o}$ field. The grid used in this model is the Arakawa $\mathrm{C}$-grid, where all the scalar quantities are positioned in the center and the vector quantities on the sides (see Fig. 7a). This allows the conservation of mass equation to be solved using a mass-conserving numerical scheme. 


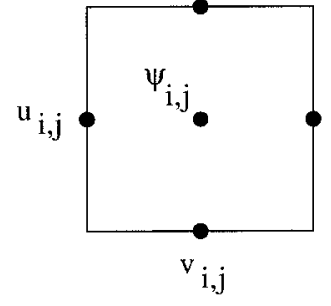

a)

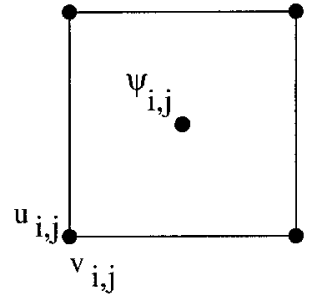

b)
FIG. 7. Location of the scalar and vector quantities on the Arakawa C-grid (a) and B-grid (b): $\Psi$ can represent the ice thickness $(h)$, concentration $(A)$, temperature $(T)$, and pressure $(p)$.

\section{a. Momentum equation}

The description of the numerical solution for the momentum equation parallels the one used in Flato and Hibler (1992). The ice thickness and concentration used in the solution of the momentum equation are first calculated from Eqs. (4) and (5) using a simple forward-intime, upwind finite-difference scheme. Neglecting the acceleration term and expressing the sea surface tilt in terms of the geostrophic ocean current $\left(f \mathbf{u}_{w}^{g}=g \mathbf{k} \times \nabla H_{d}\right)$, the momentum equation (1) can be written as follows:

$$
A\left(\mathbf{u}_{i}-\mathbf{u}_{w}^{g}\right)=\mathbf{R}-\boldsymbol{\nabla} p+\boldsymbol{\nabla} \cdot \boldsymbol{\sigma}^{\prime},
$$

where $\mathbf{R}$ is the wind-forcing term and $-\boldsymbol{\nabla} p+\boldsymbol{\nabla} \cdot \boldsymbol{\sigma}^{\prime}$ the ice interaction term. The matrix and vectors can be written as follows:

$$
\begin{aligned}
A & =\left(\begin{array}{cc}
C_{d w}^{\prime} \cos \theta_{w} & -\rho_{i} h f-C_{d w}^{\prime} \sin \theta_{w} \\
\rho_{i} h f+C_{d w}^{\prime} \sin \theta_{w} & C_{d w}^{\prime} \cos \theta_{w}
\end{array}\right) \\
\mathbf{R} & =\left(\begin{array}{l}
C_{d a}^{\prime}\left(u_{a} \cos \theta_{a}-v_{a} \sin \theta_{a}\right) \\
C_{d a}^{\prime}\left(v_{a} \cos \theta_{a}+u_{a} \sin \theta_{a}\right)
\end{array}\right) \\
\mathbf{F} & =\left(\begin{array}{l}
\frac{\partial}{\partial x}\left[\eta\left(\frac{\partial u}{\partial x}-\frac{\partial v}{\partial y}\right)\right]+\frac{\partial}{\partial y}\left[\eta\left(\frac{\partial u}{\partial y}+\frac{\partial v}{\partial x}\right)\right] \\
\frac{\partial}{\partial x}\left[\eta\left(\frac{\partial u}{\partial y}+\frac{\partial v}{\partial x}\right)\right]-\frac{\partial}{\partial y}\left[\eta\left(\frac{\partial u}{\partial x}-\frac{\partial v}{\partial y}\right)\right]
\end{array}\right),
\end{aligned}
$$

where $\mathbf{F}=\boldsymbol{\nabla} \cdot \boldsymbol{\sigma}^{\prime}$. We now seek an ice velocity field satisfying Eq. (28), subjected to the restrictions on the pressure field [Eq. (26)]. This is done in three steps. First, the free drift velocities ${ }^{1} \mathbf{u}_{i}^{f d}$ are calculated, and then used as an initial approximation to the solution of the momentum equation (28). Second, the free drift velocities and associated pressure field ( $p=0$, everywhere) are corrected using Eq. (26) and considering the term $\boldsymbol{\nabla} \cdot \boldsymbol{\sigma}^{\prime}$ a constant. Finally, the friction term is considered and the velocity field is calculated considering

\footnotetext{
${ }^{1}$ The solution of (28) without the ice interaction term included.
}

the pressure to be known. The resulting velocity field will not necessarily satisfy the restriction on pressure, and iteration between the second and the third step is therefore necessary.

The free drift velocity can be calculated analytically using the B-grid (Fig. 7b), where both components of the ice velocity are collocated, with knowledge of the wind and ocean currents at each node of the domain. In addition, the part of the forcing that is independent of the ice velocities can be calculated from the free drift velocities in the following manner:

$$
\mathbf{R}^{\prime}=\mathbf{R}+A \mathbf{u}_{w}^{g}=A \mathbf{u}_{i}^{f d} .
$$

Then $\mathbf{R}^{\prime}$ and $\mathbf{u}_{i}^{f d}$ are interpolated onto the C-grid for subsequent use in the numerical scheme. The momentum equations now take the form

$$
A \mathbf{u}_{i}=\mathbf{R}^{\prime}-\nabla p+\nabla \cdot \boldsymbol{\sigma}^{\prime} .
$$

As a second step, the free drift solution is modified to satisfy both the equation of motion (29) and the restriction equation (26). More generally, any initial guess $\left(\overline{\mathbf{u}}_{i}\right.$ and $\bar{p}$ ) satisfying Eq. (29) can be used as a starting point. Substituting the corrected fields $\left(\mathbf{u}_{i}=\overline{\mathbf{u}}_{i}+\mathbf{u}_{i}^{\prime}\right.$ and $p=\bar{p}+p^{\prime}$ ) into the equation of motion (29) and subtracting the basic state, the equation for the velocity correction can be written as

$$
A \mathbf{u}_{i}^{\prime}=-\nabla p^{\prime} \quad \text { or } \quad \mathbf{u}_{i}^{\prime}=-\frac{\nabla p^{\prime}}{C_{d w}^{\prime} \cos \theta_{w}} .
$$

The frictional term $\left(\boldsymbol{\nabla} \cdot \boldsymbol{\sigma}^{\prime}\right)$ and the off-diagonal terms of matrix $A$ are considered temporarily constant and therefore are not part of the perturbed solution. Their effect will be considered later in the solution. Upon substituting (30) into (26), the pressure field can be calculated by solving

$$
\boldsymbol{\nabla} \cdot\left(\frac{\nabla p^{\prime}}{C_{d w}^{\prime} \cos \theta_{w}}\right)=\boldsymbol{\nabla} \cdot \overline{\mathbf{u}}_{i}-2 \dot{\gamma} \tan \delta .
$$

For a simplified situation where $\delta$ is set equal to zero, this scheme will adjust the pressure $p$ in order to obtain a nondivergent velocity field. In the limit where the ice is infinitely strong in tension and compression, the final solution would be nondivergent. In practice, the ice has a finite strength in compression and little or no resistance in tension; for these reasons, regions of convergence and divergence will exist in the solution domain. If dilatation is considered $(\delta \neq 0)$, the flow field can be divergent and the pressure still positive. This would be observed when shearing occurs along sliding lines due to the rearrangement of the floes. In finite-difference form, the left-hand side of the above equation is written in the following manner:

$$
\begin{array}{r}
\boldsymbol{\nabla} \cdot\left(\frac{\nabla p^{\prime}}{C_{d w}^{\prime} \cos \theta_{w}}\right)=\frac{1}{\Delta^{2}}\left[\frac{p_{i+1, j}^{\prime}-p_{i, j}^{\prime}}{\zeta_{i+1, j}^{x}}-\frac{p_{i, j}^{\prime}-p_{i-1, j}^{\prime}}{\zeta_{i, j}^{x}}\right. \\
\left.+\frac{p_{i, j+1}^{\prime}-p_{i, j}^{\prime}}{\zeta_{i, j+1}^{y}}-\frac{p_{i, j}^{\prime}-p_{i, j-1}^{\prime}}{\zeta_{i, j}^{y}}\right],
\end{array}
$$


where $\Delta$ is the grid size and $\zeta_{i, j}^{x}\left(=C_{d w}^{\prime} \cos \theta\right)$ and $\zeta_{i, j}^{y}$ the diagonal components of the matrix $A$ evaluated on the vertical and horizontal side of the grid, respectively. This equation is solved using a Gauss-Seidel relaxation technique where the pressure $p$ is considered zero except at the point of interest $(i, j)$. Approximately 20 iterations are required to obtain the desired accuracy; the solution of this equation takes roughly $15 \%$ of the total CPU time. From these considerations, the correction on $p_{i, j}$ can be written as follows:

$$
\begin{aligned}
p_{i, j}^{\prime}= & \Delta^{2}\left(-\nabla \cdot \overline{\mathbf{u}}_{i}+2 \dot{\gamma} \tan \delta\right) \\
& \times\left(\frac{1}{\zeta_{i+1, j}^{x}}+\frac{1}{\zeta_{i, j}^{x}}+\frac{1}{\zeta_{i, j+1}^{y}}+\frac{1}{\zeta_{i, j}^{y}}\right)^{-1} .
\end{aligned}
$$

The correction on the velocities follows from Eq. (30):

$$
\begin{array}{ll}
u_{i, j}^{\prime}=-\frac{1}{\zeta_{i, j}^{x}} \frac{p_{i, j}^{\prime}}{\Delta}, & u_{i+1, j}^{\prime}=\frac{1}{\zeta_{i+1, j}^{x}} \frac{p_{i, j}^{\prime}}{\Delta}, \\
v_{i, j}^{\prime}=-\frac{1}{\zeta_{i, j}^{y}} \frac{p_{i, j}^{\prime}}{\Delta}, & v_{i, j+1}^{\prime}=\frac{1}{\zeta_{i, j+1}^{y}} \frac{p_{i, j}^{\prime}}{\Delta} .
\end{array}
$$

In the above expressions the subscript $i$ for ice was omitted to make the notation clearer.

The current value of pressure $p$ or velocity $\mathbf{u}_{i}$ is the sum of the initial value and the correction $p^{\prime}$ or $\mathbf{u}_{i}^{\prime}$. However, certain restrictions must be imposed on the pressure $p$ [see Eq. (26)]. If the pressure exceeds the maximum value in compression $\left(P_{\max }\right)$, the correction must be set equal to $P_{\max }-p$ to avoid exceeding the maximum allowable value. This will result in convergence in that grid cell. If the pressure $p$ becomes negative (tensile stress), the correction must be set equal to $-p$, resulting in a zero final pressure and divergence in that grid cell. Note that the friction term was not considered in the computation of the pressure or velocity fields. Consequently, a new correction to the velocity field is required to account for the newly computed pressure field. This is done using the following finite-difference form of the ice interaction term. For instance, the two terms in the x component of the $F$ term can be written as follows:

$$
\begin{gathered}
F_{1}=\frac{1}{\Delta}\left[\eta_{i, j}^{c}\left(\frac{u_{i+1, j}-u_{i, j}}{\Delta}-\frac{v_{i, j+1}-v_{i, j}}{\Delta}\right)\right. \\
\left.-\eta_{i-1, j}^{c}\left(\frac{u_{i, j}-u_{i-1, j}}{\Delta}-\frac{v_{i-1, j+1}-v_{i-1, j}}{\Delta}\right)\right] \\
F_{2}=\frac{1}{\Delta}\left[\eta_{i, j+1}^{n}\left(\frac{u_{i, j+1}-u_{i, j}}{\Delta}+\frac{v_{i, j+1}-v_{i-1, j+1}}{\Delta}\right)\right. \\
\left.-\eta_{i, j}^{n}\left(\frac{u_{i, j}-u_{i, j-1}}{\Delta}+\frac{v_{i, j}-v_{i-1, j}}{\Delta}\right)\right],
\end{gathered}
$$

where $\eta^{c}$ and $\eta^{n}$ are the coefficients of friction evaluated at the center of the grid cell and the node, respectively. Similar expressions can be derived for the $F_{y}$ component. Writing the complete momentum equation in finite-difference form, the velocity field can be calculated from the following:

$$
A\left(\begin{array}{l}
u_{i, j} \\
v_{i, j}
\end{array}\right)=\mathbf{R}^{\prime \prime},
$$

where $\mathbf{R}^{\prime \prime}$ comprises all the forcing terms and the offdiagonal velocity terms independent of $\mathbf{u}_{i, j}$. Again, this is solved using a Gauss-Seidel relaxation technique on the above equation. Typically, 30 iterations are needed to obtain the desired accuracy; the solution of this equation takes approximately $25 \%$ of the total CPU time. Since the resulting velocity field will not satisfy the restriction on pressure imposed by the closure scheme given by Eq. (26), it is necessary to iterate a few times (about 4 or 5 ) between the two algorithms.

\section{b. Energy equations}

The ocean temperature is updated from the various atmosphere-ocean and ice-ocean heat fluxes using a simple forward-in-time finite-difference method. The atmosphere and ice surface temperatures are then calculated using the new ocean temperature field. The forcing terms for the atmosphere are linearized about their values at the previous time step and can all be written in terms of the atmospheric temperature $T_{a}$, the ocean temperature $T_{o}$, the ice and land surface temperatures $T_{i}$ and $T_{l}$, and the ice base temperature $T_{i b}$. In the following, the ice base temperature is assumed to be equal to the ocean temperature. As a result, sensible heat transfer between the ice and the ocean only occurs when the ocean temperature rises above the ice melting point. Furthermore, the ice surface temperature can be expressed in terms of the atmospheric temperature as follows [see Eq. (10)]:

$$
\begin{aligned}
-K_{i} \frac{T_{i}-T_{o}}{h / A} & =Q_{i a}=a_{o}+a_{1} T_{i}-a_{2} T_{a}, \\
T_{i} & =\frac{-a_{o}+a_{2} T_{a}+K_{i} A T_{o} / h}{K_{i} A / h+a_{1}} .
\end{aligned}
$$

A similar expression can be derived for the land surface temperature. The atmosphere energy equation now constitutes a linear advection-diffusion equation in $T_{a}$ of the form:

$$
A \mathbf{T}_{a}=\mathbf{R}^{\prime \prime \prime},
$$

where $\mathbf{R}^{\prime \prime \prime}$ represents the total heat fluxes from the surface to the atmosphere. This equation is solved using the alternating direction implicit (ADI) method [see Press et al. (1990)]. In the first substep, we solve for the temperatures in the even rows ( $x$ direction) of the physical domain assuming the odd row temperatures are known. The same approach is then used for the odd row, even column, and 


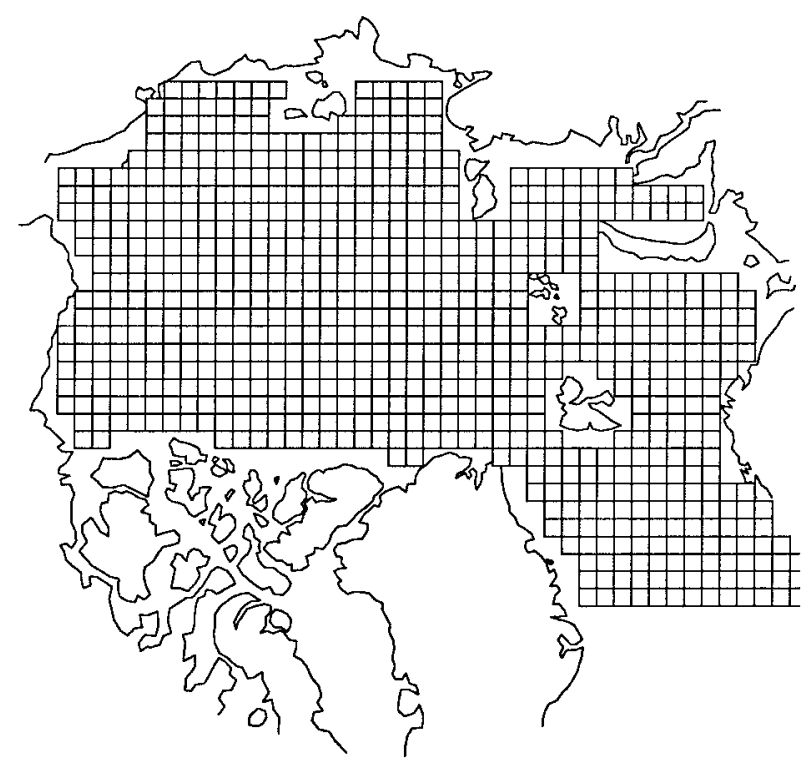

FIG. 8. Computational grid used in the simulation.

odd column temperatures. The advantage of this method is that each substep requires only the solution of a tridiagonal matrix, which can be solved easily by standard techniques. After a few iterations (4 or 5), the solution converged to the required accuracy. Once the atmospheric temperature is known, the ice and land surface temperature can be easily calculated [e.g., see Eq. (33)].

\section{Results}

Results from a simulation of the sea ice cover over a seasonal cycle in the Arctic Ocean and surrounding seas, using this model, are presented in this section. A Cartesian mesh with a grid resolution of $111 \mathrm{~km}$ is used on a polar stereographic projection of the physical domain (see Fig. 8). At high latitudes, the variation of the Coriolis parameter with latitude is small and the $f$-plane approximation is used. The model is forced with prescribed climatological monthly mean wind stresses, obtained from the 1959-89 National Meteorological Center (NMC, now known as the National Centers for Environmental Prediction) sea level pressure analysis. These stresses are assumed to represent the midmonth situation. The wind stress field at a particular day is calculated from a linear interpolation of the two closest midmonth values. Spatially varying, but steady ocean currents were calculated from a single layer reducedgravity model, appropriate for large-scale flows, in which the acceleration term in the momentum equation is ignored, friction is represented using a linear drag law, and the normal velocity component is specified at open boundaries. In the Bering Strait, the normal velocity was chosen so as to obtain a constant inflow of $1 \mathrm{~Sv}\left(\mathrm{~Sv} \equiv 10^{6} \mathrm{~m}^{3} \mathrm{~s}^{-1}\right)$ into the Arctic, and the velocity field in the North Atlantic was specified from Levitus sea surface elevation data and scaled in such a way as to obtain no accumulation of water in the Arctic domain. Finally, the solar forcing is the daily averaged value corrected for an 80\% cloud cover (Laevastu 1960).

The boundary conditions for the ice dynamic equations are zero normal and tangential velocity at a solid boundary and free outflow $(p=0)$ at an open boundary (Hibler 1979). For the atmospheric thermodynamic equations, the temperature at the boundary is specified from monthly climatology. The temperature on a given day is calculated as a weighted average of the midmonth climatological values. These temperatures were calculated from the NMC 850-mb height and temperature fields, assuming a linear temperature profile from the $1013-\mathrm{mb}$ and 850-mb levels. For the ocean, the temperatures at open boundaries are also specified from monthly climatologies extracted from the Levitus data. At continental boundaries, the ocean heat flux is considered zero (a continent is regarded as a perfect insulator). The initial conditions for the ice model, used in all simulations, are 1-m ice thickness and $80 \%$ ice concentration. For the ocean, the temperature is set at the freezing point temperature $\left(-1.8^{\circ} \mathrm{C}\right)$ of Arctic Ocean surface waters everywhere.

In this study, an attempt was made to include the effect of surface roughness in the drag coefficients. Quadratic drag coefficients ranging from 1 to $6 \times 10^{-3}$ were measured in the last 30 years with the more recent measurements being at the upper end of this range. This is explained by the fact that the measurements have been made over increasingly rough surfaces and perhaps under increasingly unstable stratifications conditions (Smith 1990). Since the surface roughness depends on ridging intensity, which in turn influences ice thickness, both the air-ice and ocean-ice drag coefficients are assumed to vary linearly with ice thickness in the range between 1 and $5 \mathrm{~m}$ (Tremblay and Mysak 1997). A list of all the physical parameters and constants used in the simulations are given in Table 1. Finally, the internal angle of friction is considered constant and equal to $30 \mathrm{deg}$.

The model was integrated for 10 years to reach a stable seasonal cycle using a 1-day time step and a zero angle of dilatation. The results shown are the simulated March lead pattern, the annual mean climatological ice velocity field, and the midmonth March and September ice thickness distributions, which also include the ice edge position for these months. The effect of including dilatation, associated with shearing deformation, on ice thickness distribution is also discussed for the midMarch results. Calculated atmosphere and ocean midMarch temperature fields are also presented. The model results are compared with sonar data for ice thickness, buoy data for ice velocity fields, satellite data for ice extent, NMC data for the atmosphere temperature, and Levitus data for the ocean temperature.

\section{a. Lead pattern and ice velocity field}

In the continuum approach used here, we do not keep track of the exact position of each ice floe for all time; 
TABle 1. Physical parameters and constants used in the simulation.

\begin{tabular}{|c|c|c|}
\hline Variable & Symbol & Value \\
\hline Atmospheric albedo & $\alpha_{a}$ & 0.26 \\
\hline Ice albedo & $\alpha_{i}$ & 0.70 \\
\hline Land albedo & $\alpha_{l}$ & 0.20 \\
\hline Ocean albedo & $\alpha_{o}$ & 0.17 \\
\hline Angle of dilatancy & $\delta$ & $10 \mathrm{deg}$ \\
\hline Atmospheric emissivity & $\epsilon_{a}$ & 0.88 \\
\hline Ice emissivity & $\epsilon_{i}$ & 0.97 \\
\hline Land emissivity & $\epsilon_{l}$ & 0.90 \\
\hline Ocean emissivity & $\epsilon_{o}$ & 0.96 \\
\hline Planetary emissivity & $\epsilon_{p}$ & 0.50 \\
\hline Internal angle of friction & $\phi$ & $30 \mathrm{deg}$ \\
\hline Maximum ice viscosity & $\eta_{m}$ & $1 \times 10^{12} \mathrm{~kg} \mathrm{~m}^{-1} \mathrm{~s}^{-1}$ \\
\hline Air density & $\rho_{a}$ & $1.3 \mathrm{~kg} \mathrm{~m}^{-3}$ \\
\hline Ice density & $\rho_{i}$ & $900 \mathrm{~kg} \mathrm{~m}^{-3}$ \\
\hline Water density & $\rho_{w}$ & $10^{3} \mathrm{~kg} \mathrm{~m}^{-3}$ \\
\hline Stefan-Boltzmann constant & $\sigma$ & $5.67 \times 10^{-8} \mathrm{~W}\left(\mathrm{~m}^{2} \mathrm{~K}^{4}\right)^{-1}$ \\
\hline Air and water turning angle & $\theta_{a}, \theta_{w}$ & $25 \mathrm{deg}$ \\
\hline Saturation vapor pressure constants & $A_{1}, A_{2}$ & $7.5,35.86$ \\
\hline Ice strength parameter & $C$ & 20 \\
\hline Air drag coefficient $(h=1 \mathrm{~m})$ & $C_{d a}$ & $1.2 \times 10^{-3}$ \\
\hline Water drag coefficient $(h=1 \mathrm{~m})$ & $C_{d w}^{d a}$ & $5.5 \times 10^{-3}$ \\
\hline Latent heat transfer coefficient & $C_{\text {lat }}$ & $1 \times 10^{-3}$ \\
\hline Specific heat of air & $C_{p a}$ & $1 \times 10^{3} \mathrm{~J}(\mathrm{~kg} \mathrm{~K})^{-1}$ \\
\hline Specific heat of ice & $C_{p i}^{p a}$ & $2 \times 10^{3} \mathrm{~J}(\mathrm{~kg} \mathrm{~K})^{-1}$ \\
\hline Specific heat of land & $C_{p l}$ & $0.7 \times 10^{3} \mathrm{~J}(\mathrm{~kg} \mathrm{~K})^{-1}$ \\
\hline Specific heat of water & $C_{p w}^{p i}$ & $4 \times 10^{3} \mathrm{~J}(\mathrm{~kg} \mathrm{~K})^{-1}$ \\
\hline Sensible heat coefficient & $C_{\text {sens }}$ & $1 \times 10^{-3}$ \\
\hline Atmospheric scale height & $H_{a}^{\text {sens }}$ & $7 \times 10^{3} \mathrm{~m}$ \\
\hline Land thickness & $H_{l}$ & $6 \mathrm{~m}$ \\
\hline Ocean mixed layer depth & $H_{0}$ & $60 \mathrm{~m}$ \\
\hline Diffusion coefficient for $A$ & $K_{A}$ & $50 \mathrm{~m}^{2} \mathrm{~s}^{-1}$ \\
\hline Atmospheric diffusion coefficient & $K_{a}^{A}$ & $5 \times 10^{12} \mathrm{~m}^{2} \mathrm{~s}^{-1}$ \\
\hline Diffusion coefficient for $h$ & $K_{h}$ & $50 \mathrm{~m}^{2} \mathrm{~s}^{-1}$ \\
\hline Ice thermal conductivity & $K_{i}$ & $2 \mathrm{~W}\left(\mathrm{~m}^{2} \mathrm{~K}\right)^{-1}-1$ \\
\hline Land thermal conductivity & $K_{l}$ & $2 \mathrm{~W}\left(\mathrm{~m}^{2} \mathrm{~K}\right)^{-1}-1$ \\
\hline Ocean diffusion coefficient & $K_{o}$ & $1 \times 10^{10} \mathrm{~m}^{2} \mathrm{~s}^{-1}$ \\
\hline Latent heat of evaporation & $L_{e}$ & $2.50 \times 10^{6} \mathrm{~J} \mathrm{~kg}^{-1}$ \\
\hline Latent heat of fusion & $L_{f}$ & $3.30 \times 10^{5} \mathrm{~J} \mathrm{~kg}^{-1}$ \\
\hline Latent heat of sublimation & $L_{s}$ & $2.83 \times 10^{6} \mathrm{~J} \mathrm{~kg}^{-1}$ \\
\hline Ice strength in compression & $P_{\max }$ & $7 \times 10^{3}\left(\mathrm{~N} \mathrm{~m}^{-2}\right)^{-1}$ \\
\hline Sea level pressure & $P_{s}$ & $101.3 \times 10^{3} \mathrm{~Pa}$ \\
\hline Ocean freezing point & $T_{f p}$ & $-1.8^{\circ} \mathrm{C}$ \\
\hline Freshwater freezing point & $T_{f i}$ & $0^{\circ} \mathrm{C}$ \\
\hline Land base temperature & $T_{l b}$ & $6.0^{\circ} \mathrm{C}$ \\
\hline Atmospheric absorptivity & $a_{a}$ & 0.25 \\
\hline Coriolis parameter & $f$ & $1.5 \times 10^{-4} \mathrm{~s}^{-1}$ \\
\hline Gravitational acceleration & $g$ & $9.81 \mathrm{~m} \mathrm{~s}^{-2}$ \\
\hline Demarcation thickness between thick and thin ice & $h_{0}$ & $0.5 \mathrm{~m}$ \\
\hline
\end{tabular}

consequently, the exact position of leads and sliding of groups of floes relative to one another cannot be resolved. Instead leads will appear as regions where large shear strain rates are present. In order to evaluate the ability of the model to reproduce the large-scale lead patterns often observed. (e.g., Fig. 2c), a shear strain rate map is shown in Fig. 9 for mid-March. Of particular interest is the shear band extending from the western Canadian Arctic Archipelago (Prince Patrick Island) to the North Pole. This modeled feature agrees well with the observed lead seen in the SSMI satellite observations (Fig. 2c). North of Greenland, no shear lines are observed. There, the flow is unbounded to the east and the shear force required to induce sliding motion is much smaller. For this reason, it does not show up as a distinct feature in the observations. Other high shear regions (not shown here) are also present adjacent to coastlines; however, in these regions, the ice pressure is typically much smaller.

The simulated annual-mean velocity field is shown in Fig. 10a, along with an annual climatological velocity pattern derived from buoy drift measurements from the Arctic Buoy Program (Fig. 10b). Qualitatively speaking, the Beaufort gyre and the Transpolar Drift Stream are well simulated; however, with the center of the gyre positioned slightly westward from its climatological location. Model results obtained with the Bering Strait closed (not shown here) depict the Beaufort gyre center to be quite westward of its observed position. The open- 


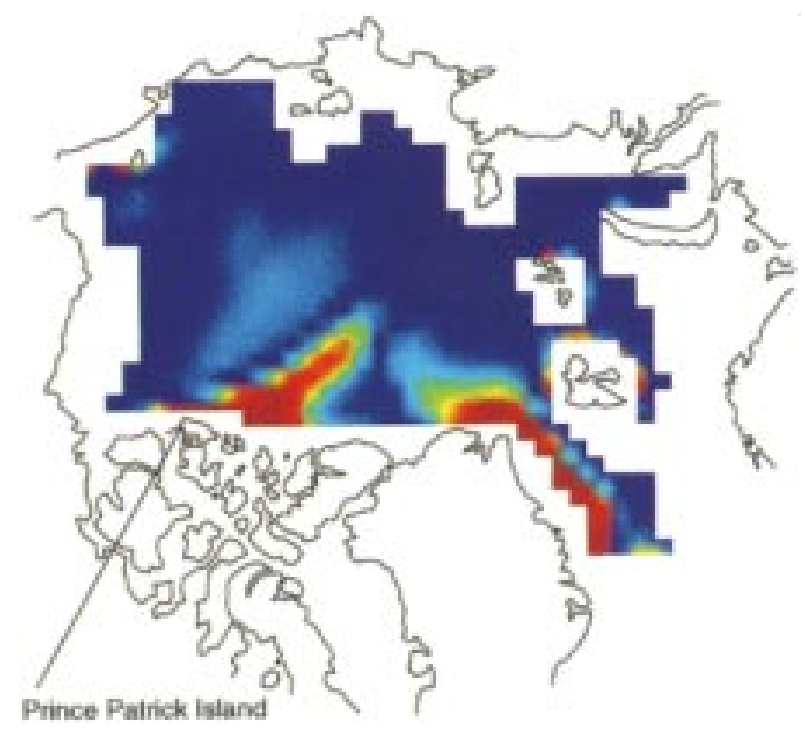

FIG. 9. Shear strain rate [denominator of Eq. (27)] color map. Regions of high shear strain rate are indicated by the warm colors. Note that the shear strain rate is scaled by the internal ice pressure to focus attention on places where the ice interactions are significant.

ing of the Bering Strait significantly improves the simulation and plays an important role in determining the velocity field in the east Siberian side of the gyre. It is important to note that the model produces a wedge of very slowly moving ice at the dividing line between the ice caught in the Beaufort gyre and that leaving the Arctic through Fram Strait. In this region, we often have creeping flow, which occurs when only small deformations in the ice field are present. In this figure, the region of high shear strain rate is also apparent at the interface between the relatively fast moving ice of the Beaufort gyre and the relatively still ice north of Greenland. The ice velocity in the gyre is of the order of 2 $3 \mathrm{~cm} \mathrm{~s}^{-1}$, in agreement with measurements by Colony and Thorndike (1984), who quote an average value of about $2.5 \mathrm{~cm} \mathrm{~s}^{-1}$. The ice coming out of the Arctic through Fram Strait has a typical velocity of $5 \mathrm{~cm} \mathrm{~s}^{-1}$, which is also in good agreement with observations.

\section{b. March ice thickness and concentration fields}

Figure 11 shows the simulated mid-March thickness distribution in the Arctic, which can be compared with the sonar measurements reported by Bourke and Garrett (1987). The ice edge position, defined as the 5-tenths ice concentration contour, is also included in these figures. Before discussing Fig. 11, it is useful to review the model results without ice dynamics. Runs with a thermodynamiconly model (not shown here) show thickness contours more or less concentric about the North Pole, with a bias of thicker ice toward the Canadian Arctic Islands, where the coldest temperatures are registered. Also, the heat transported by the North Atlantic Drift distorts the model thickness contours in the GIN (Greenland-Iceland-Norwegian) Seas, keeping the Norwegian and a good part of the Barent Sea clear of ice. Finally, in a model without ice dynamics, the maximum ice thickness in the central Arctic is thinner than the observed values due to the absence of mechanically ridged ice. As can be seen, (cf. Figs. 11a and 11b), the inclusion of ice dynamics significantly improves the solution. The ice thickness contour patterns reproduce the observations well, including the double-humped distribution poleward of the northern $\mathrm{Ca}$ nadian islands, where there is a maximum ice thickness of $7 \mathrm{~m}$. One-meter ice thicknesses are also present in the model near the Asian continent except in the Laptev and Siberian Sea where thicker than observed ice is present. The modeled ice free region in the North Atlantic now extends over the whole Norwegian and Barents Seas due to the prevailing wind blowing ice eastward. In the winter, whether the Bering Strait is open or closed has a strong influence on the ice thickness distribution in the Chukchi Sea. When open, the prescribed ocean velocity profile produces significantly thicker ice poleward of Bering Strait. However, the temperature of water entering the domain is very close to the freezing point and does not have a significant influence on the growth of ice in this region.

In the Barent Sea, the ice margin is very well reproduced; however, in the Greenland Sea the ice edge is too far east. This is due to the nature of the prescribed ocean currents, which are characterized by a weak recirculation of water in the Greenland Sea. This discrepancy can also be seen by comparing the model and observed ocean temperature patterns (Fig. 12) where colder temperatures are generally present south of Svalbard, in the Greenland Sea. The generally well-positioned ice edge in the model is remarkable, given that the atmospheric and ocean temperatures are calculated rather than prescribed. For the atmosphere, the model and observed temperatures for the month of March are shown on Fig. 13. The model air temperature in the central Arctic (Fig. 13a) is slightly too cold due to the thicker ice present in the Laptev and East Siberian Seas. However, the model temperature contours are in very good agreement with the NMC analysis in the Barent, Norwegian, and Greenland Seas where a tongue of warm water keeps the region ice free and the overlying air warm.

\section{c. March ice thickness distribution with dilatation}

A key quantity to be able to predict in climate studies at high latitudes is the heat lost by the ocean to the atmosphere. To obtain a good estimate of this quantity, both a realistic ice thickness distribution and a good representation of the lead distribution is necessary. Although the lead area represents a very small fraction of the total Arctic domain (typically $1 \%$ or $2 \%$ ), the amount of heat lost through the leads is of the same order of magnitude as the heat lost through the ice by conduction. Observations of the Arctic cover show that regions of open water are always present even in the central Arctic and far inside 

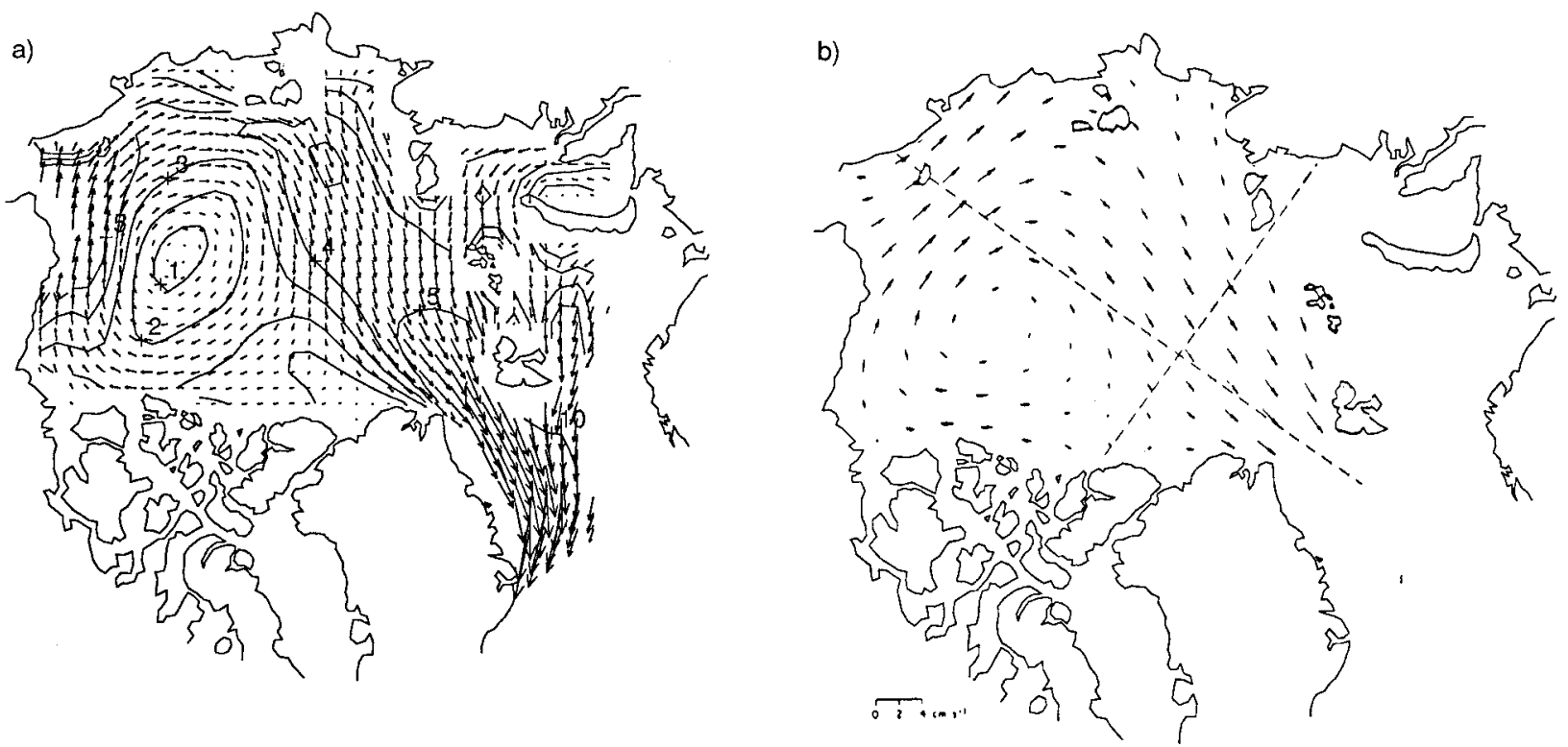

FIG. 10. Simulated (a) and observed (reproduced from Colony and Thorndike 1984) (b) annual mean velocity field.

the ice margin. In some previous modeling studies, the ice concentration was capped to $99 \%$ to account for this fact in an ad hoc manner. In this study a constant angle of dilatancy of $10 \mathrm{deg}$ is used, to account for the opening of leads along sliding lines. In reality, when a lead is formed, large heat loss from the ocean is present and thin ice reforms rapidly. This thin ice is very weak in compression and will ridge easily once it is subjected to compression. In this manner ice thickness can build up easily even in regions where thick multiyear ice is present. In this model, this is simulated by shear deformation with a small amount of divergence. This will cause the ice concentration to drop below $100 \%$ and will result in an increased heat loss to the atmosphere. Finally, the reduction in ice concentration will result in a smaller ice strength in compression, which will make it easier to ridge. Figure 14 shows the mid-March ice thickness difference field with and without dilatation after a 2-month integration starting from the mid-January dilatation-free results. We observe that the ice thickness is larger in the high-shear region north of the Canadian Islands when dilatation is considered. After a 2-month integration, differences of $20 \mathrm{~cm}$ in
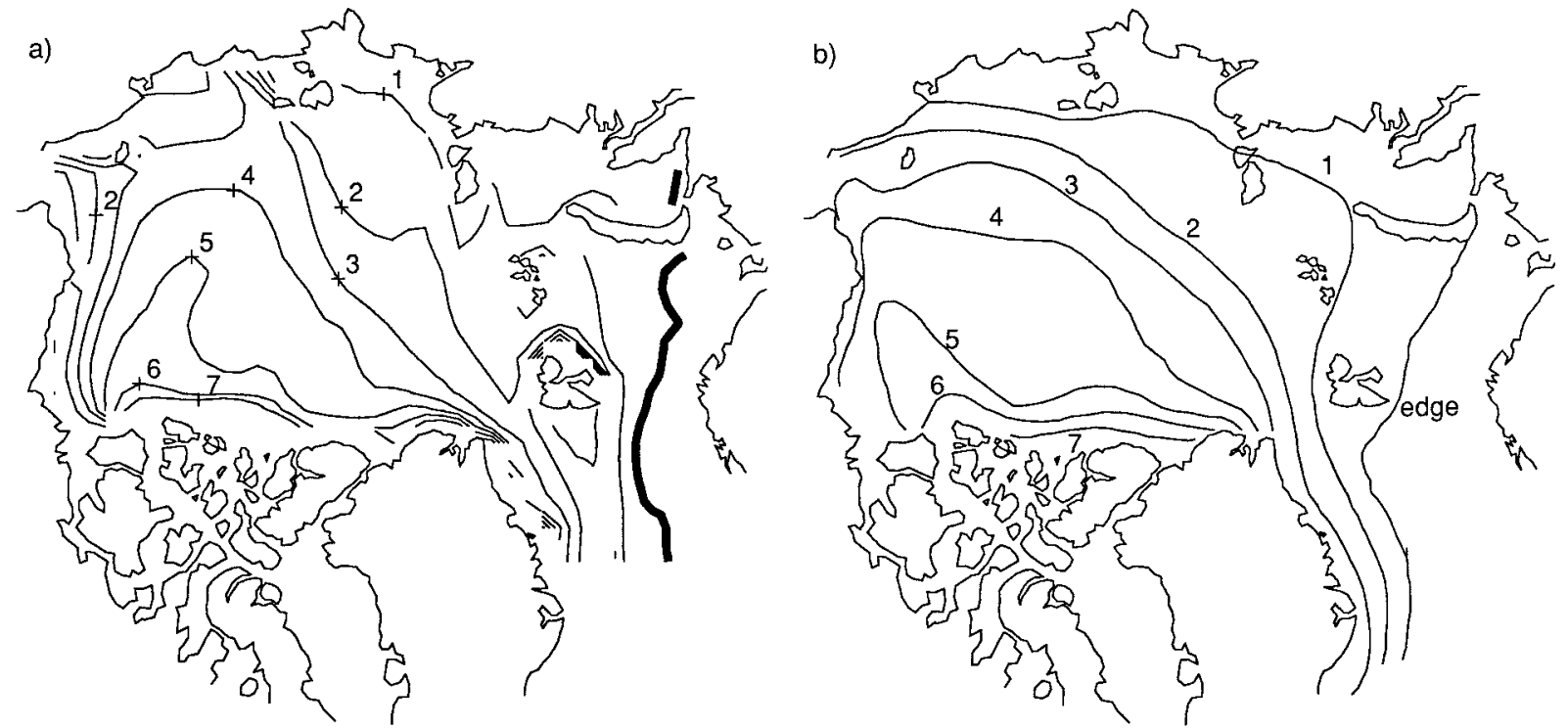

FIG. 11. Simulated March ice thickness distribution in meters (a) and observed ice thickness from sonar data (reproduced from Bourke and Garrett 1987) (b). The broad dark line denotes the ice edge. 

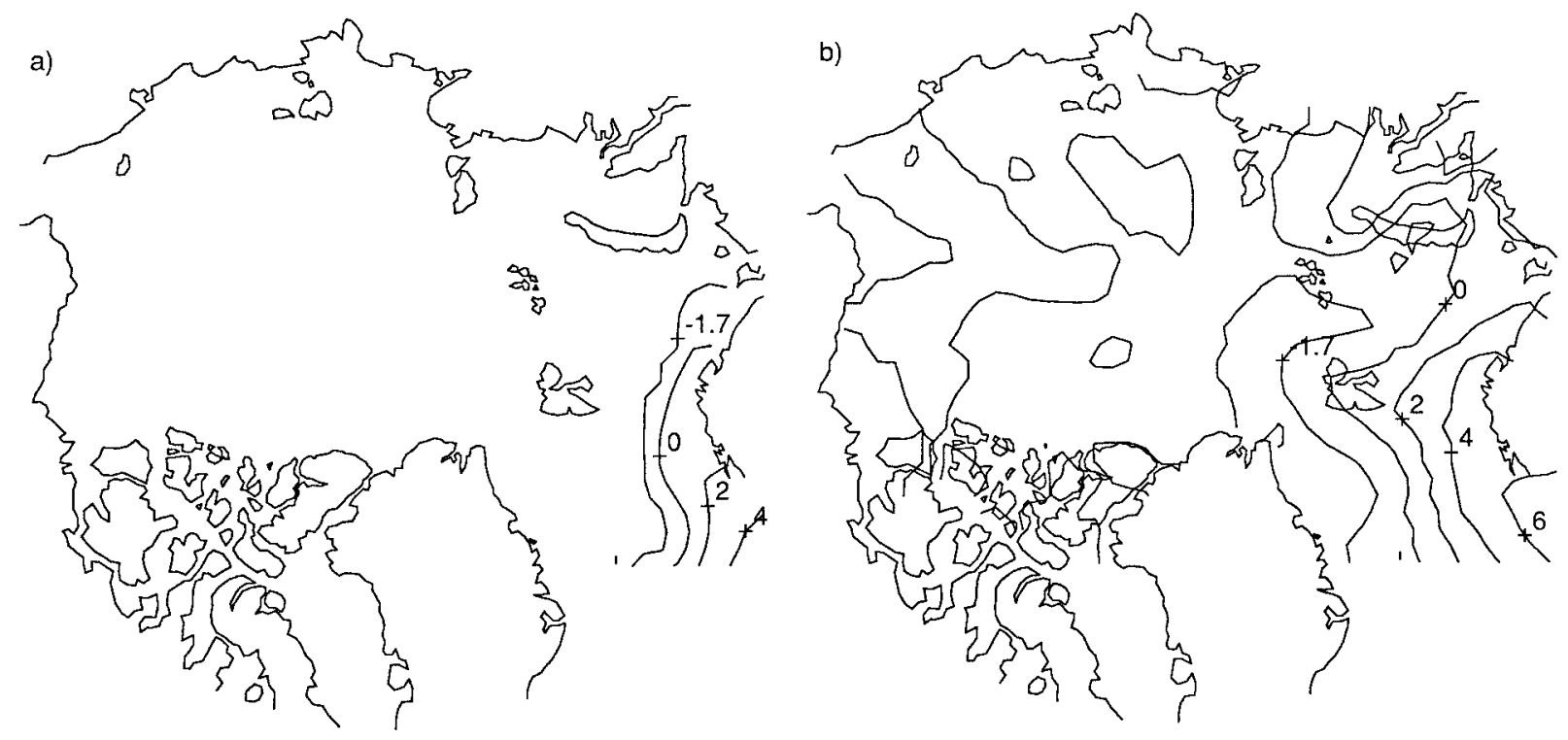

FIG. 12. Simulated March ocean temperature distribution (degrees Celsius) (a) and observed ocean temperature distribution from Levitus (b).

ice thickness are obtained. The effect of dilatation will play a larger role poleward of the Canadian Islands, where observations show high lead activity, and in coastal regions where shear deformations are induced by the presence of boundaries.

\section{d. September ice thickness and concentration fields}

Figures $15 \mathrm{a}$ and $15 \mathrm{~b}$ show the simulated and observed ice thickness distribution for the month of September. Again the ice edge is indicated in these figures. The calculated ice thicknesses are in reasonably good agree- ment with the measurements. However, the ice thickness peak is too far west, being north of the Canadian Archipelago instead of north of Greenland. The climatological wind pattern reverses in the summer (McLaren et al. 1987) and is partly responsible for the observed shift; this seems to be underrepresented in the model results. In the summer, the open boundary condition at the Bering Strait has an influence on the ice thickness distribution in the Chukchi Sea, both through the advection of warm waters from the North Pacific and the different ocean current pattern beneath the ice.

Simulated results from a thermodynamic only model
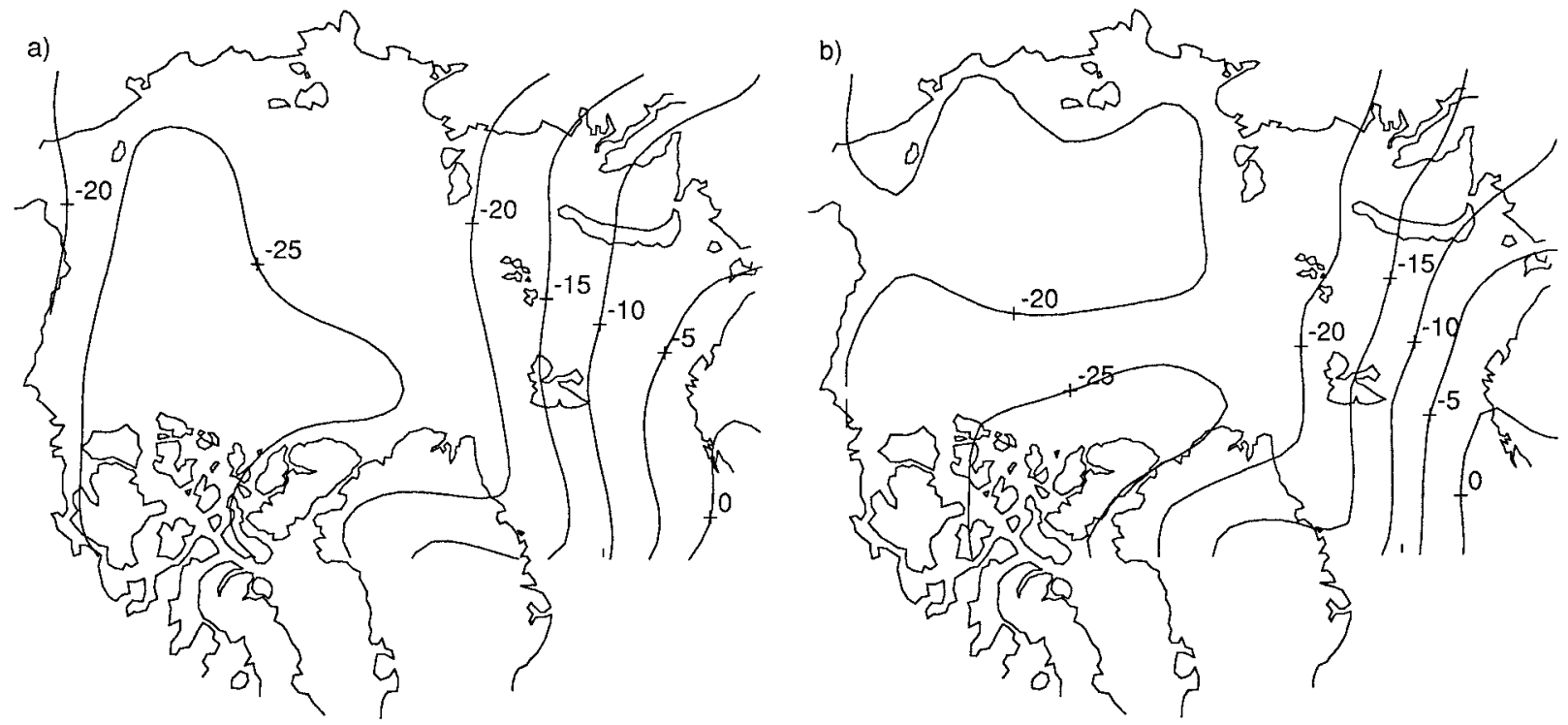

FIG. 13. Simulated March atmosphere temperature distribution (degrees Celsius) (a), and NMC derived atmosphere temperature distribution $(b)$. 


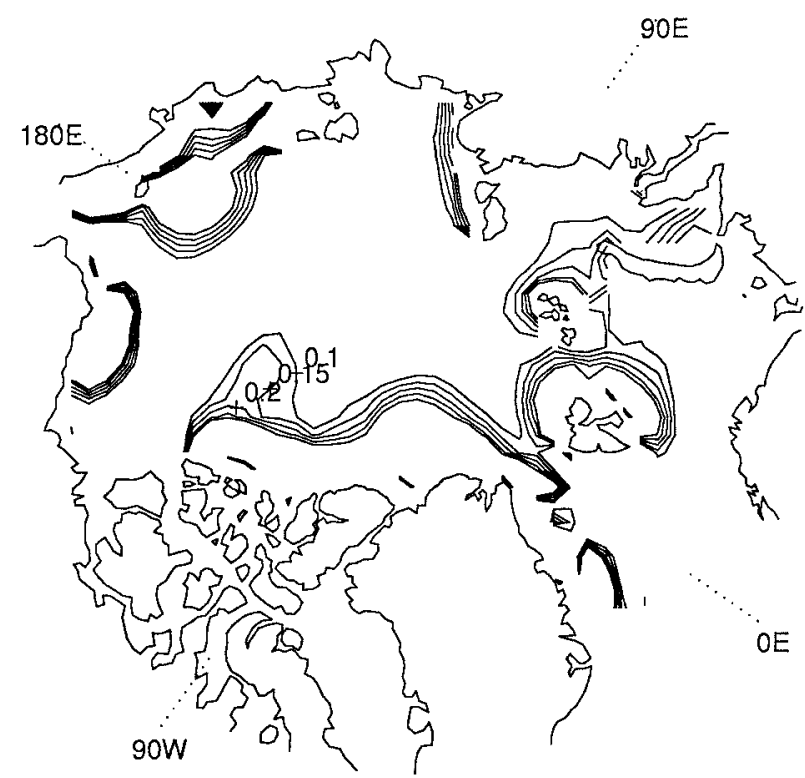

FIG. 14. Ice thickness difference field with and without dilatation (in meters).

(not shown here) show an ice edge position in the Barents Sea, which is slightly too far south, and all of the Kara, Laptev, and East Siberian sea remain ice covered, unlike in the observations. The Beaufort and Chukchi seas are partly ice free but the ice edge is not well positioned. Including ice dynamics in the model yields a much improved modeled ice edge position. In the North Atlantic, much less ice accumulates in the winter due to the prevailing southwesterly winds present in the cold months. Consequently, the whole Barents Sea becomes ice free in the summer, as shown in Fig. 15a.
Moreover, the Kara and Laptev Seas are ice free, and the ice edge position at the edge of the Beaufort Sea agrees very well with observations. The position of this ice edge coincides with the demarcation line between first year and multiyear ice at the edge of the Beaufort Sea. As a result, the Beaufort Sea fills with first year ice in the winter, which melts away in the summer. Finally, the East Siberian Sea remains ice covered in the summer unlike in the observations. The details of the ocean current pattern are believed to play a large role in the position of the ice edge in this area.

\section{Conclusions}

In the present model, sea ice is considered as a largescale granular material, that is, a collection of ice floes. The deformation in the ice field is considered slow enough that the floes remain in contact during deformation, allowing frictional forces to act and retard the sea ice drift. At a point, this frictional force is considered proportional to the normal force keeping the floes together. This situation is analogous to the case of dynamic friction between two dry surfaces. The model also allows for a variable internal angle of friction and a certain amount of dilatation in the granular media, which depends on the distribution of the ice floes and the deformation history. This dilatation causes leads to open and consequently always allows a small percentage of the ocean surface to be ice free, which is commonly observed in the Arctic. This behavior arises naturally from simple considerations based on the behavior of sea ice at the microscopic level, and eliminates the need to rely on the parameterization of lead opening. In this study, the angle of friction is considered constant and the amount of dilatation is proportional to the shear defor-

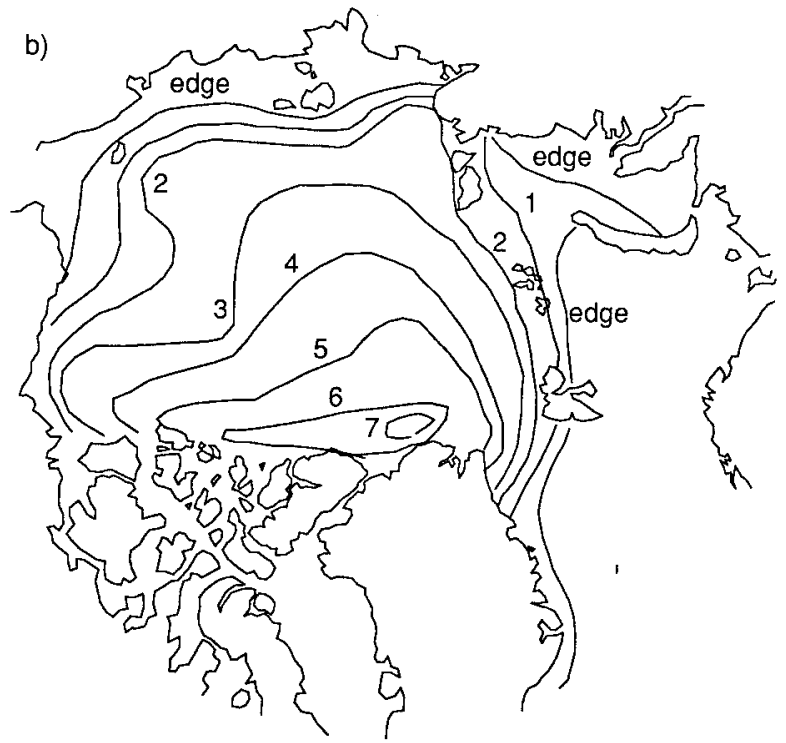

FIG. 15. Simulated average September ice thickness field in meters (a) and observed ice thickness (reproduced from Bourke and Garrett 1987) (b). The heavy dark line denotes the ice edge. 
mation. The drag coefficients used in this study are proportional to ice thickness in order to account for the fact that thick ice is formed by ridging and is usually rougher.

A long-term (10-year) integration of the thermodynamically coupled ocean-ice-atmosphere model could reproduce many observed features of the Arctic sea ice cover, both in winter and in summer. Regions of largescale sliding observed along leads extending from the Beaufort Sea to the central Arctic are well reproduced by the model. In addition, the observed opening of leads associated with this shear deformation is well simulated. The ice thickness distribution over the entire Arctic agrees quite well with sonar measurements, for both winter and summer, with maximum and minimum ice thicknesses of 7 and $1 \mathrm{~m}$, respectively. This is partly due to the linear dependence of the drag coefficients on ice thickness (Tremblay and Mysak 1997). The ice edge position in summer also agrees well with satellite observation. In particular, the model produces ice free regions in the marginal seas during this season.

Acknowledgments. We are very grateful to Prof. K. Hutter and Dr. N. Gray from the Technische Hochschule in Darmstadt for their careful review of the manuscript and suggestions for its improvement. L.-B.T. is grateful to the NSERC and FCAR for financial support during the course of this work and L.A.M. is indebted to AES and NSERC for financial support. Finally, we thank the National Snow and Data Center for providing us with $\mathrm{SSM} / \mathrm{I}$ brightness temperature data for this study.

\section{REFERENCES}

Babic, M., H. H. Shen, and H. T. Shen, 1990: The stress tensor in granular shear flows of uniform, deformable disks at high solids concentrations. J. Fluid Mech., 219, 81-118.

Balendran, B., and S. Nemat-Nasser, 1993: Double sliding model for cyclic deformation of granular materials, including dilatancy effects. J. Mech. Phys. Solids, 41, 573-612.

Bourke, R. H., and R. P. Garrett, 1987: Sea ice thickness distribution in the Arctic Ocean. Cold Reg. Sci. Technol., 13, 259-280.

Campbell, C., 1990: Rapid granular flows. Annu. Rev. Fluid Mech., 22, 57-92.

Colony, R., and A. S. Thorndike, 1984: An estimate of the mean field of Arctic sea ice motion. J. Geophys. Res., 89, 10623-10 629.

Coon, M. D., S. A. Maykut, R. S. Pritchard, D. A. Rothrock, and A. S. Thorndike, 1974: Modelling the pack ice as an elastic plastic material. AIDJEX Bull., 24, 1-105.

Doronin, Y. P., 1970: On a method of calculating the compactness and drift of ice floes, (English transl.). AIDJEX Bull., 3, 22-39.

Erlingsson, B., 1988: Two-dimensional deformation pattern in sea ice. J. Glaciol., 34, 301-308.

Flato, G. M., and W. D. Hibler III, 1991: An initial numerical investigation of the extent of sea ice ridging. Ann. Glaciol., 15, 31-36.

- , and - 1992: Modeling pack ice as a cavitating fluid. $J$. Phys. Oceanogr., 22, 626-651.

Gray, J. M. N. T., and L. W. Morland, 1994: A two-dimensional model for the dynamics of sea ice. Philos. Trans. Roy. Soc. London, 347, 219-290.
Hibler, W. D., III, 1977: A viscous sea ice law as a stochastic average of plasticity. J. Geophys. Res., 82, 3932-2938.

- 1979: A dynamic thermodynamic sea ice model. J. Phys. Oceanogr., 9, 815-846.

— fluctuations of Arctic sea ice. J. Phys. Oceanogr., 12, 1514-1523.

Holland D. M., 1993: Numerical Simulation of the Arctic Sea Ice and Ocean Circulation. Ph.D. thesis, McGill University, 203 pp. [Available from Dept. of Atmosphere and Oceanic Science, McGill University, 805 Sherbrooke St. West, Montreal, PQ H3A 2K6, Canada.]

- L. A. Mysak, and D. K. Manak, 1993: Sensitivity study of a dynamic-thermodynamic sea-ice model. J. Geophys. Res., 98, 2561-2586.

Hopkins, M. A., 1994: On the ridging of intact lead ice. J. Geophys. Res., 99, 16351-16360.

Hutter, K., and K. R. Rajagopal, 1994: On flows of granular materials. Cont. Mech. Thermodyn., 6, 81-139.

Kozo, T. L., R. W. Fett, L. D. Farmer, and D. S. Sodhi, 1992: Clues to causes of deformation features in coastal sea ice. Eos Trans. Amer. Geophys. Union, 73, 385-389.

Laevastu, T., 1960: Factors affecting the temperature of the surface layer of the sea. Comment. Phys. Math., 25(1), 1-134.

Marko, J. R., and R. E. Thomson, 1977: Rectilinear and internal motions in the ice pack of the western Arctic Ocean. J. Geophys. Res., 82, 979-987.

Maykut, G. A., and D. K. Perovitch, 1987: The role of shortwave radiation in the summer decay of a sea ice cover. J. Geophys. Res., 92, 7032-7044.

McLaren, A. S., M. C. Serreze, and R. G. Barry, 1987: Seasonal variations of sea ice motion in the Canada basin and their implications. Geophys. Res. Lett., 14, 1123-1126.

McPhee, M. G., 1975: Ice-ocean momentum transfer for the AIDJEX ice model. AIDJEX Bull., 29, 93-111.

Nikiforov, Y. B., Z. M. Gudkovitch, Y. I. Yefimov, and M. A. Romanov, 1970: Principles of a method for computing ice redistribution under the influence of wind during the navigation period in Arctic seas. AIDJEX Bull., 3, 40-64.

Overland, J. E., and C. H. Pease, 1988: Modeling ice dynamics of coastal seas. J. Geophys. Res., 93, 15619-15 637.

Press, W. H., B. P. Flannery, S. A. Teukolsky, and W. T. Vetterling, 1990: Numerical recipes. 2 ed. Cambridge University Press, 848 pp.

Pritchard, R., 1981: Mechanical behaviour of pack ice. Mechanics of Structured Media, E. Selvadurai, Ed., Elsevier, 371-405.

- 1988: Mathematical characteristics of sea ice dynamics models. J. Geophys. Res., 93(C12), 15 609-15618.

Shen, H. H., W. D. Hibler III, and M. Leppäranta, 1986: On applying granular flow theory to a deforming broken ice field. Acta Mech., 63, 143-160.

Smith, W. O., 1990: Polar Oceanography. Part A: Physical Science. Academic Press, 34 pp.

Spencer, A. J. M., 1964: A theory of the kinematics of ideal soils under plane strain conditions. J. Mech. Phys. Solids, 12, 337-351.

Stern, H. L., D. A. Rothrock, and R. Kwok, 1995: Open water production in Arctic sea ice: Satellite measurements and model parameterizations. J. Geophys. Res., 100, 20 601-20612.

Thorndike, A. S., 1986: Kinematics of sea ice. The Geophysics of Sea Ice, N. Untersteiner, Ed., Series B: Physics, Vol. 146, Plenum, 489-549,

Tremblay, L.-B., and L. A. Mysak, 1997: The possible effects of including ridge-related roughness in air-ice drag parameterization: A sensitivity study. Ann. Glaciol., in press.

Ukita, J., and R. E. Moritz, 1995: Yield curves and flow rules of pack ice. J. Geophys. Res. 100, 4545-4557.

Zillman, J. W., 1972: A study of some aspect of the radiation heat budget of the Southern Hemisphere oceans. Tech. Rep. 26. [Available from Bureau of Meteorology, Department of Interior, G.P.O. Box 787, Canberra, Australia 2601. 